\title{
APLICAÇÃO DE GASES NOBRES E SEUS ISÓTOPOS NA HIDROGEOLOGIA
}

\author{
Roberto Eduardo KIRCHHEIM \\ Kiang Huang CHANG \\ Didier GASTMANS \\ Sibele EZAKI \\ Márcia Regina STRADIOTO
}

\begin{abstract}
RESUMO
À medida que as demandas por água aumentam, torna-se imperativo conhecer as dinâmicas de circulação das águas subterrâneas nos aquíferos, informação indispensável para a gestão sustentável dos mesmos. As técnicas envolvendo os traçadores ambientais e, dentre estes, especificamente aqueles inerentes aos gases nobres e seus isótopos, fornecem valiosas informações, como por exemplo, os tempos de residência das águas subterrâneas e as paleotemperaturas de recarga. Os gases nobres, representados pelo $\mathrm{He}$, $\mathrm{Ne}, \mathrm{Ar}, \mathrm{Kr}$ e Xe possuem propriedades físicas e químicas que variam sistematicamente com seu peso atômico, além de amplas variações em suas composições isotópicas decorrentes de processos nucleares a partir de elementos parentais relativamente mais abundantes. Pelo fato de serem inertes, os gases nobres não sofrem alterações químicas e isotópicas nas interações água-rocha. Sua presença nas águas subterrâneas pode ser interpretada como uma mistura entre a componente atmosférica e a componente não atmosférica (radiogênica e/ou terrigênica). Enquanto a componente atmosférica guarda registros de dinâmicas pretéritas associadas aos processos de recarga e, portanto, de paleoambientes e clima, as componentes não atmosféricas, essencialmente associadas aos isótopos de $\mathrm{He}\left({ }^{3} \mathrm{He}\right.$ e $\left.{ }^{4} \mathrm{He}\right)$, assim como isótopos radiogênicos, entre eles ${ }^{81} \mathrm{Kr}$, ${ }^{85} \mathrm{Kr}$ e ${ }^{39} \mathrm{Ar}$, fornecem informação de caráter cronológico. O presente artigo apresenta uma completa revisão bibliográfica sobre o significado da concentração dos gases nobres dissolvidos em água, suas respectivas componentes e os caminhos metodológicos empregados para extrair informações para a hidrogeologia. Da mesma forma, são apresentadas as práticas amostrais de campo, as estratégias analíticas e os caminhos metodológicos para o tratamento dos dados, a partir da alusão aos principais trabalhos desenvolvidos pela comunidade científica internacional. Finalmente, são apresentadas e discutidas as iniciativas pioneiras em gases nobres no Brasil, com destaque para as aplicações no âmbito do Sistema Aquífero Guarani. Dessa forma, o presente trabalho fornece uma ampla visão do uso dos gases nobres e informações relevantes para a difusão das referidas técnicas no país.
\end{abstract}

Palavras-chaves: Gases nobres; Água subterrânea; Datação; Paleotemperatura.

\section{ABSTRACT}

APPLICATION OF NOBLE GASES AND THEIR ISOTOPES IN THE HYDROGEOLOGY. As the demands for water increase, it is imperative to better assess the dynamics of groundwater circulation in aquifers, information that is considered indispensable for sustainable management. The techniques involving environmental tracers and, among these, specifically those inherent to noble gas isotopes, provide valuable information, such as groundwater residence times and recharge paleotemperatures. Noble gases, namely $\mathrm{He}, \mathrm{Ne}, \mathrm{Ar}, \mathrm{Kr}$ and $\mathrm{Xe}$, have physical and chemical 
properties that vary systematically with their atomic weight, in addition to wide variations in their isotopic compositions resulting from nuclear processes from relatively more abundant parent elements. Because they are inert, noble gases do not undergo chemical and isotopic changes in water-rock interactions. Their presence in groundwater can be interpreted as mixing of atmospheric and non-atmospheric components (radiogenic and/or terrigenous). While the atmospheric component keeps records of past dynamics associated with recharge processes and, therefore, of paleoenvironments and climate, the non-atmospheric components, essentially associated with $\mathrm{He}$ isotopes $\left({ }^{3} \mathrm{He}\right.$ and ${ }^{4} \mathrm{He}$ ), as well as radiogenic isotopes, including ${ }^{81} \mathrm{Kr},{ }^{85} \mathrm{Kr}$ and ${ }^{39} \mathrm{Ar}$, provide valuable chronological information. This paper presents a complete bibliographic review on the meaning of the concentration of noble gases dissolved in water, their respective components and the methodological paths used to extract hydrogeological information. In the same way, field sampling practices, analytical strategies and methodological paths for data treatment are presented on the basis of the allusion to the main works developed by the international scientific community. Finally, the antecedents of noble gases in Brazil are presented and discussed, with emphasis on the Guarani Aquifer System, which has been the object of pioneering and current development with the application of noble gases. The paper provides a broad view of the use of noble gases and relevant information for the dissemination of these techniques in Brazil.

Keywords: Noble gases; Groundwater; Residence Time; Paleotemperatures.

\section{INTRODUÇÃO}

A água subterrânea constitui recurso vital para $\mathrm{o}$ atendimento das demandas domésticas, da agricultura e da indústria ao longo da história humana. As extrações desse recurso intensificaram-se a partir da década de 1950, em função de avanços tecnológicos, como conhecimento geológico, técnicas construtivas, tecnologia de bombeamento e eletrificação rural.

\section{Conforme FAMIGLIETTI \& FERGUSON} (2021) e JASECHKO \& PERRONE (2021), em virtude de secas, uso crônico e excessivo, vulnerabilidade natural à contaminação e falta de uma gestão eficaz, os níveis potenciométricos seguem decrescendo com perdas na qualidade das águas subterrâneas.

No Brasil, apesar da aparente abundância em recursos hídricos superficiais e subterrâneos, há registros de conflitos relacionados à quantidade e ou qualidade dos mesmos (CONICELLI et al. 2021). Avaliações específicas e aprofundadas destes cenários sugerem, invariavelmente, a existência de gargalos financeiros, técnicos e institucionais, e nem sempre as águas subterrâneas recebem a atenção necessária, sendo em muitos casos relegada a uma condição de solução paliativa e imediatista, mesmo que sua relevância na contabilidade hídrica prove o contrário.
Informações relacionadas à movimentação da água nos aquíferos, base para a gestão efetiva dos mesmos, podem ser obtidas a partir de traçadores ambientais na hidrogeologia. Dentre estes traçadores, os gases nobres (doravante GN), incluindo os seus isótopos, se destacam como apropriados para estimar tempos de residência das águas subterrâneas e paleotemperaturas de recarga (TGN) (LU et al. 2014).

Pelo fato de serem inertes e terem isótopos produzidos pelo decaimento natural de radionuclídeos, os GN não sofrem alterações químicas e isotópicas nas interações água-rocha (PINTI \& MARTY 1998). As variações isotópicas dos GN permitem que os mesmos sejam usados como traçadores de idades de larga amplitude temporal (COOK 2020), desde juvenis com meses $\left({ }^{3} \mathrm{H},{ }^{3} \mathrm{H} /{ }^{3} \mathrm{He}\right)$ até antigas com centenas/milhares $\left({ }^{39} \mathrm{Ar},{ }^{4} \mathrm{He}\right)$ e até milhões de anos $\left({ }^{4} \mathrm{He},{ }^{81} \mathrm{Kr}\right)$.

Qualquer água em equilíbrio com a atmosfera, antes de ser incorporada às águas subterrâneas, pode ser considerada como um repositório de informações ambientais pretéritas. KIPFER et al. (2002) refere-se a esta proposição como sendo um axioma, aceito como uma verdade de caráter consensual e âncora para dedução de outras conclusões inerentes ao uso das técnicas envolvendo os GN.

O uso de GN e seus isótopos na hidrogeologia pode ser considerado ainda limitado no Brasil 
(STUTE et al. 1995, KIMMELMANN et al. 1995, AGGARWAL et al. 2015, CHATTON et al. 2016). A partir da experiência acumulada nos principais aquíferos do mundo e, no Brasil, principalmente como resultado das iniciativas no Sistema Aquífero Guarani (SAG), tornam-se claras as amplas e valiosas aplicações potenciais dos GN no contexto nacional, independente da escala de abordagem e/ou do tipo de arcabouço geológico-estrutural específico.

O presente estudo apresenta os principais conceitos e particularidades metodológicas envolvendo a aplicação de GN na hidrogeologia, com o objetivo de apoiar e despertar o interesse em seu uso.

\section{GASES NOBRES}

Os GN constituem o grupo 18 (VIIIa) da tabela periódica, cujas propriedades apresentam pouca variação, razão pela qual, experimentalmente, são abordados de forma coletiva. Sua denominação como sendo "gases raros" denota sua relativa escassez na natureza; são considerados elementos traços por excelência, muito embora a concentração do elemento Ar na atmosfera componha $1 \%$ da composição.

O comportamento dos GN na natureza é governado apenas por processos físicos relativamente simples como difusão, dissolução, adsorção, partição e transformações nucleares. Por esta razão, são considerados excelentes traçadores geoquímicos para investigar sistemas ambientais e geológicos (AESCHBACH-HERTIG et al. 1999). O atributo "gases nobres" e/ou "gases inertes" deve-se à resistência com que estes elementos se engajam em reações químicas. Não significa que não o venham a fazer, porém, quando o fazem, é sempre a partir de interações baseadas em forças de Van der Waals (OZIMA \& PODOSEK 2002).

É justamente esta escassez, traduzida em valores de background baixíssimos, que permite que efeitos que não sejam intrinsicamente característicos dos GN possam ser detectados a partir dos mesmos, tornando-os traçadores em potencial (OZIMA $\&$ PODOSEK 2002) (Figura 1).

De acordo com PORCELLI et al. (2002) uma expressiva parte das informações disponíveis sobre o sistema terrestre e solar advém da observação dos GN. Suas variações isotópicas refletem processos de diferenciação planetária que geraram fracionamento entre os GN e seus elementos parentais (PORCELLI \& BALLENTINE 2002). A diferenciação planetária em manto e crosta continental, as diferentes taxas de produção radiogênica de GN (a partir de U, Th e K) e o escape pretérito de gases para a atmosfera resultaram na formação de reservatórios (manto, crosta e atmosfera) com abundância e assinaturas isotópicas distintas. Existem vários processos (reações) geradores da grande variação isotópica de GN observada na natureza, e que ocorrem em maior ou menor intensidade de acordo com o reservatório avaliado. De forma geral, estas reações podem ser do tipo nucleogênicas, radiogênicas e fissiogênicas, incluindo reações de espalação e fissão espontânea. BALLENTINE \& BURNARD (2002), BALLENTINE et al. (2002) e GRAHAM (2002) oferecem uma ampla revisão dos processos de formação de isótopos de GN. As reações nucleares não produzem apenas isótopos está-

\section{8}
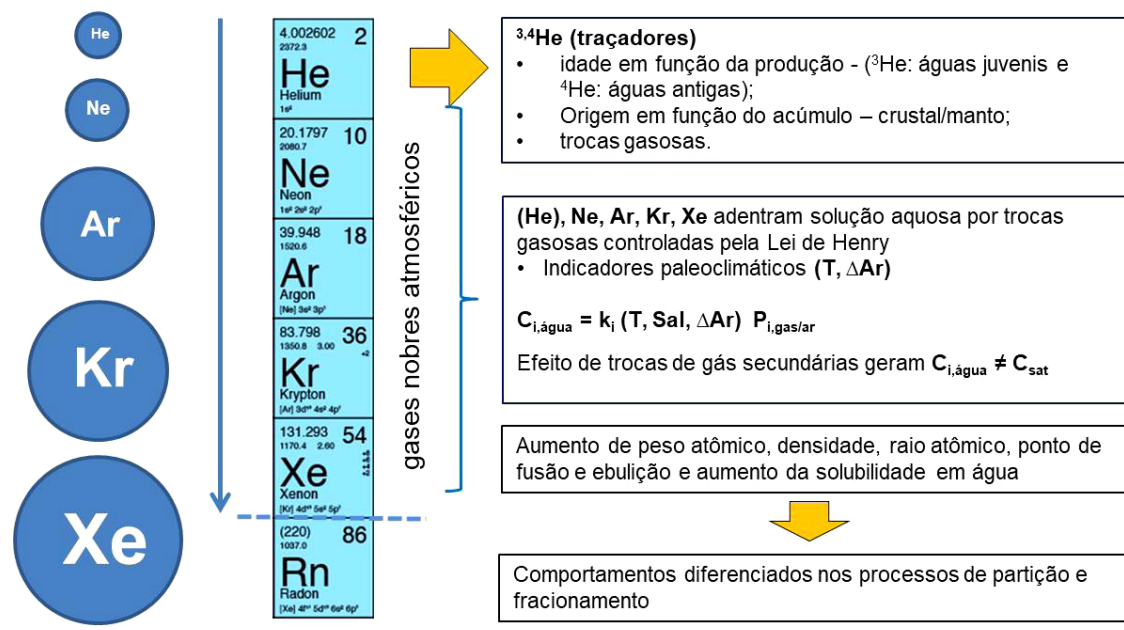

FIGURA 1 - Síntese do uso de GN em estudos hidrogeológicos. Modificado de KIPFER (2018). 
veis, mas também isótopos radioativos, com as mesmas características de inabilidade de participarem de reações químicas. Alterações em suas concentrações decorrem de processos físicos, como produção-decaimento radiogênico e mistura.

Os GN possuem propriedades físicas e químicas que variam sistematicamente com seu peso atômico, além de amplas variações em suas composições isotópicas decorrentes de processos nucleares a partir de elementos parentais relativamente mais abundantes.

Enquanto nos demais campos da geoquímica os GN de origem atmosférica são considerados “contaminação", nas águas subterrâneas os GN conformam importante e abundante parcela (KIPFER et al. 2002). As concentrações destes isótopos radioativos de GN podem ser usadas para calcular o tempo decorrido desde o instante em que o sistema comporta-se como isotopicamente fechado, ou seja, o tempo no qual o decaimento passa a ser o único processo determinante de alteração das respectivas concentrações. De acordo com BETHKE \& JOHNSON (2008), esta afirmação ampara-se no conceito de fluxo a partir do modelo em pistão, a partir do qual, a recarga de um volume de água que se processou em um determinado local migrou ao longo de uma linha de fluxo até sua posição local de coleta e análise isotópica. Vale lembrar que as referidas concentrações podem ser alteradas por processos denominados de dispersão hidrodinâmica (CASTRO \& GOBLET 2005, BETHKE \& JOHNSON 2008).

Alguns destes isótopos possuem meia vida similar ao tempo de renovação da água em sistemas naturais e podem ser usados para determinar o tempo de residência. No âmbito supergênico (atmosfera e hidrosfera) os GN fornecem elementos decisivos para o entendimento dos padrões de fluxo em sistemas hidrológicos e bacias oceânicas, além de constituírem-se em traçadores de idades e indicadores paleoclimáticos.

$\mathrm{O}$ advento de modernas técnicas analíticas permitiu a determinação de GN e seus isótopos nos mais variados tipos de meios, tanto geológicos como cosmogênicos. Os progressos na sua compreensão geoquímica estiveram subordinados ao ritmo do desenvolvimento das técnicas de espectrometria de massa (KIPFER et al. 2002). Espectrômetros de massa de ressonância magnética com resolução capaz de medir as razões isotópicas de ${ }^{3} \mathrm{He} / 4 \mathrm{He}$ foram descritos de forma pioneira por MAMYRIN et al. (1969) e MAMYRIN \& TOLSTIKHIN (1984).

\section{GASES NOBRES EM ÁGUAS SUBTERRÂNEAS}

Os GN são encontrados nas águas subterrâneas e sua abundância pode ser interpretada como uma mistura das componentes atmosférica e não atmosférica. A componente atmosférica é composta das concentrações devido ao equilíbrio com o ar atmosférico $\left(\mathrm{C}_{\mathrm{eq}}\right)$ e à parcela de excesso de ar $\left(\mathrm{C}_{\mathrm{eA}}\right)$, conforme será definido a seguir. A componente não atmosférica, por sua vez, é produzida pelo decaimento radioativo ou indiretamente por subsequentes reações nucleares desencadeadas inicialmente por processos de desintegração radioativa (KIPFER et al. 2002). Esta componente é denominada de radiogênica $\left(\mathrm{C}_{\mathrm{rad}}\right)$ em função dos processos que a originam. Os autores acima reconhecem como gases nobres ou componentes terrigêni$\cos \left(\mathrm{C}_{\mathrm{ter}}\right)$, aqueles formados em diferentes compartimentos geoquímicos sólidos da terra (crosta terrestre; manto, normalmente observada em regiões ativas vulcânicas e de tectonismo extensional).

A resolução do sistema de equações (Figura 2) a partir das técnicas de modelagem inversa, incluindo o desenvolvimento dos métodos de estimação da componente de excesso de ar $\left(\mathrm{C}_{\mathrm{eA}}\right)$, fornece insumos para a estimação das temperaturas de recarga a partir dos gases nobres (TGN) e das componentes não atmosféricas para efeitos

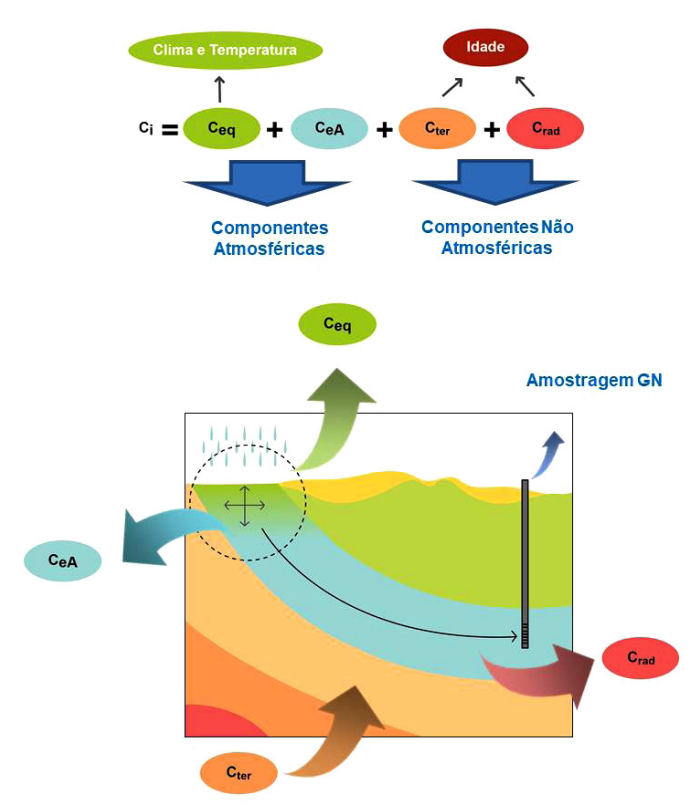

FIGURA 2 - Modelo conceitual sobre a mistura de diferentes componentes de GN nas soluções de águas subterrâneas. Extraído de KIRCHHEIM (2021). 
de datação (AESCHBACH-HERTIG et al. 1999, BALLENTINE \& HALL 1999).

A concentração de um determinado GN medida em laboratório, denominada de $\mathrm{Ci}_{\mathrm{m}}$, representa uma mistura destas componentes em diferentes proporções (KIPFER et al. 2002) (Figura 2).

De acordo com KIPFER et al. (2002), o entendimento e a quantificação parcial destas distintas componentes que compõem a concentração medida dos GN é o desafio, cuja solução permite suas aplicações na hidrogeologia. Enquanto a componente atmosférica de GN pode ser interpretada em termos das condições físicas e climáticas que prevaleciam durante os eventos de recarga, as parcelas terrigênicas e radiogênicas de GN fornecem informação sobre os tempos de residência da água no substrato aquífero e a origem dos fluidos, respectivamente.

De forma distinta aos demais GN, o He e, secundariamente também o Ar, possuem componentes não atmosféricas. Vale ressaltar que o He total é constituído pela soma da concentração presente de seus isótopos ${ }^{4} \mathrm{He} \mathrm{e}^{3} \mathrm{He}$, cada qual com expressivas componentes não atmosféricas específicas e que precisam ser mensuradas (SCHLOSSER et al. 1989). O ${ }^{3} \mathrm{He}$ possui uma componente radiogênica, também denominada de tritiogênica (formada a partir do decaimento radiogênico do trítio $-{ }^{3} \mathrm{H}$ ).

Para que se possa interpretar e usar as informações das concentrações medidas de GN é necessário estimar suas contribuições individuais, ou seja, separar as componentes que contribuem para as concentrações totais de cada um deles, e às respectivas razões isotópicas, no caso do He. A sepa- ração destas componentes baseia-se em algumas premissas: (i) cada um dos reservatórios naturais de GN contribui com uma parcela bem conhecida e parcial da concentração total de GN em uma determinada amostra; (ii) a amostra de água subterrânea coletada deve ser representativa de um único aquífero, sem ter sido afetada por mistura ou difusão. A mistura de águas de origens distintas e com diferentes temperaturas de equilíbrio com o ar resulta em uma composição final cuja temperatura de equilíbrio se desconhece e que não mais pode ser interpretada como uma soma de componentes parciais.

Todas as técnicas de separação de componentes partem do princípio de que as concentrações de GN medidas em uma determinada amostra representam a soma dos componentes parciais, conforme a Equação 1 (KIPFER et al. 2002):

$$
\mathrm{Ci}_{\mathrm{m}}=\mathrm{Ci}_{\mathrm{eq}}+\mathrm{Ci}_{\mathrm{eA}}+\mathrm{Ci}_{\text {ter }}+\mathrm{Ci}_{\text {rad }} \text { Eq. } 1
$$

Importante ressaltar que para permitir que o sistema de equações das componentes de GN seja considerado possível, a contribuição não atmosférica do Ar deve ser negligenciável; o mesmo deve valer para o caso do $\mathrm{Ne}, \mathrm{Kr}$ e Xe (LEHMANN et al. 1993). Para os GN acima citados vale a Equação parcial 2 (MATSUMOTO et al. 2018).

$$
\mathrm{Ci}_{\mathrm{m}}=\mathrm{Ci}_{\mathrm{eq}}+\mathrm{Ci}_{\mathrm{eA}}
$$

Estabelece-se, portanto, um sistema de equações, composto das equações parciais para cada um dos GN e isótopos de $\mathrm{He}$, conforme ilustrado na figura 3.

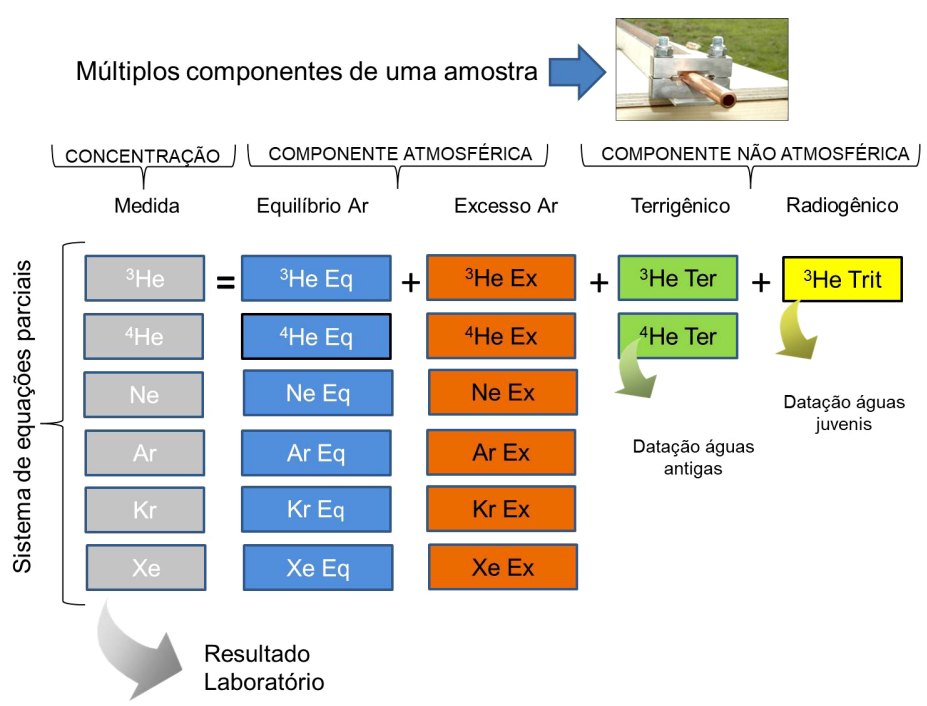

FIGURA 3 - O Sistema de Equações representa as distintas componentes para cada GN e ou isótopo de GN. Modificado de MATSUMOTO (2018). 


\subsection{Concentração atmosférica de equilíbrio}

A concentração de GN na fase aquosa é governada pela solubilidade de GN atmosféricos na água superficial. As respectivas concentrações de equilíbrio dependem da temperatura $(\mathrm{T})$ e salinidade (S) da água, assim como da pressão atmosférica $(\mathrm{P})$. Amostras de água com uma interface livre com a atmosfera tendem a dissolver GN até que seja alcançado o estado de equilíbrio termodinâmico entre as fases aquosas e gasosas, trocas estas que a literatura reconhece como sendo muito rápidas (KIPFER et al. 2002).

A solubilidade aumenta com a massa atômica devido à menor energia cinética (menor difusão) das moléculas maiores. $\mathrm{O} \mathrm{He}$, mais leve, apresenta a menor solubilidade, enquanto o Xe, mais pesado, é o GN de maior solubilidade. O Ar é o GN mais abundante na atmosfera e por isso, possui a maior concentração dissolvida na água em equilíbrio com o ar. O Xe é menos abundante na atmosfera e, apesar de sua alta solubilidade, é o que apresenta a mais baixa concentração em solução aquosa equilibrada com o ar.

A partição de gás na interface entre ar e água pode ser descrita pela lei de Henry, que assume que as concentrações de GN nas duas fases são proporcionais entre si, conforme equação 3 .

$$
\mathrm{C}_{\mathrm{i}}^{\text {gas }} / \mathrm{C}_{\mathrm{i}}^{\text {agua }}=\mathrm{H}_{\mathrm{i}}{ }^{\prime}\left(\mathrm{T}, \mathrm{C}_{\mathrm{j}}^{\text {agua }}, \ldots\right) \approx \mathrm{H}_{\mathrm{i}}{ }^{\prime}(\mathrm{T}, \mathrm{S}) \quad \text { Eq. } 3
$$

Onde $\mathrm{C}_{\mathrm{i}}{ }^{\text {gas }}$ e $\mathrm{C}_{\mathrm{i}}^{\text {agua }}$ denotam as concentrações de um gás específico nas fases gasosas e aquosas e $\mathrm{H}_{\mathrm{i}}{ }^{\prime}$ representa a constante de Henry adimensional, a qual depende de $\mathrm{T}$ e $\mathrm{H}_{\mathrm{i}}{ }^{\prime}$ da concentração de todas as demais espécies dissolvidas $\mathrm{C}_{\mathrm{j}}$. Para a maior parte das aplicações a dependência de $\mathrm{H}_{\mathrm{i}}{ }^{\prime}$ das interações entre os solutos $\left(\mathrm{C}_{\mathrm{j}}\right)$ pode ser negligenciada porque estas concentrações são baixas, considerando-se que os GN atmosféricos dissolvidos se comportam como GN ideais. Logo, o efeito total dos solutos na dissolução de cada um dos GN específicos pode ser expresso a partir da dependência de $\mathrm{H}_{\mathrm{i}}{ }^{\prime}$ à salinidade $(\mathrm{S})$. As concentrações de equilíbrio atmosférico podem ser calculadas a partir da solubilidade fornecida em diversas referências, tais como: (i) WEISS $(1970,1971)$ e WEISS \& KYSER (1978), que fornecem valores de concentrações de solubilidade em equilíbrio para pressões totais de $1 \mathrm{~atm}$ e; (ii) CLEVER (1979a, b; 1980) para solubilidades em fração molar e incorporando os coeficientes de salinidade de SMITH \& KENNEDY (1983).
KIPFER et al. (2002) sugerem nova formulação generalizada a partir de equações de regressão do tipo Setchenov para acomodar a dependência no conteúdo salino.

\subsection{Concentração de excesso de ar}

As águas subterrâneas podem conter concentrações de GN maiores do que as esperadas em função do equilíbrio alcançado com a atmosfera, ou seja, $\mathrm{C}_{\mathrm{m}}>\mathrm{C}_{\mathrm{eq}}$. HEATON \& VOGEL (1979, 1981) chamaram estas concentrações adicionais de Excesso de $\operatorname{Ar}\left(\mathrm{C}_{\mathrm{e} A}\right)$.

Esta componente é gerada pelo reequilíbrio entre a água e o ar aprisionado na forma de bolhas, que pode cobrir até cerca de $10 \%$ da porosidade da matriz na zona parcialmente saturada. Durante o desenvolvimento de eventos de recarga, a ascensão freática acaba por atrapar bolhas de ar na zona não saturada. Um leve incremento de pressão na água subterrânea contendo microbolhas de ar conduz a um novo estado de equilíbrio entre o ar aprisionado e a água. A figura 4 ilustra de forma sintética o modelo conceitual de formação da parcela de excesso de ar $\left(\mathrm{C}_{\mathrm{eA}}\right)$ nos $\mathrm{GN}$.

Existem diferentes modelos que descrevem a $\mathrm{C}_{\mathrm{eA}}$ de GN nas águas subterrâneas, incluindo a predição de fracionamento que se processa na referida parcela: (i) Modelo de Excesso Sem Fracionamento - UA (STUTE 1989, 1995b); (ii) Modelo de Reequilíbrio - PR/MR (STUTE 1989, STUTE et al. 1995); (iii) Modelo de Equilíbrio fechado com aprisionamento de ar - CE (AESCHBACHHERTIG et al. 2000); (iv) Modelo da Pressão Negativa - NP (MERCURY et al. 2004); (v)

$$
\Delta \mathrm{CeA}=\left(\frac{\mathrm{C}_{\text {medido(GN) }}}{\mathrm{C}_{\text {equilibrio (GN) }}}-1\right) \times 100
$$

Intervalo típico: $\Delta \sim 20 \%$ a $50 \%$

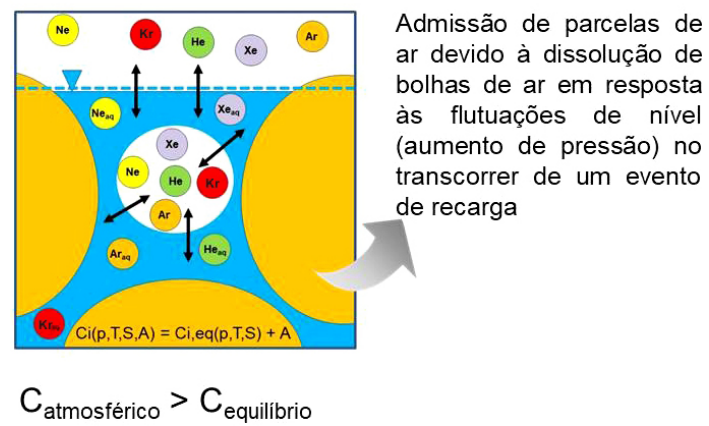

FIGURA 4 - Modelo conceitual de formação da componente de excesso de ar $\left(\mathrm{C}_{\mathrm{eA}}\right)$. Modificado de KIPFER et al. (2002). 
Modelo de Depleção de Oxigênio - OD (HALL et al. 2005); (vi) Modelo de Difusão de Gás - GR (SUN et al. 2008).

Diferentes difusividades moleculares levam a fracionamento da $\mathrm{C}_{\mathrm{eA}}$ em relação ao ar atmosférico. O modelo PR prediz que a depleção das frações iniciais de $\mathrm{C}_{\mathrm{eA}}$ é maior nos gases nobres leves, enquanto os mais pesados estariam relativamente enriquecidos nos excessos remanescentes. Apesar de aceito o fato de que a formação da $\mathrm{C}_{\mathrm{eA}}$ produza um padrão de enriquecimento de GN pesados nas águas subterrâneas, os processos físicos que o governa são muito distintos. Conforme AESCHBACH \& SOLOMON (2013), ocorre um fracionamento em relação às parcelas de ar considerado puro. Para o caso de quantidades moderadas de $\mathrm{C}_{\mathrm{eA}}$ e fracionamento pequeno, os modelos levam a predições similares de fracionamento de GN. Segundo estes mesmos autores, em casos de fracionamento expressivo, os modelos diferem significativamente em suas predições. O Modelo CE relaciona a quantidade e o fracionamento do $\mathrm{C}_{\mathrm{eA}}$ diretamente com parâmetros físicos observáveis e que controlam a partição na interface ar/água. Devido a este fato, este modelo tende a ser o mais aceito e utilizado (KIPFER et al. 2002).

Diversos pesquisadores, como STUTE et al. (1995), AESCHBACH-HERTIG et al. (1999, 2000), BALLENTINE \& HALL (1999),
WEYHENMEYER et al. (2000) e HOLOCHER et al. (2001), demonstraram que, muito embora grande parte da parcela $\mathrm{C}_{\mathrm{eA}}$ seja de fato atmosférica, existem algumas parcelas de $\mathrm{C}_{\mathrm{eA}}$ que não ocorrem devido à injeção, aprisionamento e dissolução completa de ar puro no subsolo. A compreensão, estimação e aplicação da parcela de $\mathrm{C}_{\mathrm{eA}}$ é um assunto que suscita intensos e atuais debates.

\subsection{Concentração não atmosférica}

Segundo ANDREWS (1985), os isótopos ${ }^{3} \mathrm{He},{ }^{4} \mathrm{He} \mathrm{e}{ }^{40} \mathrm{Ar}$ são produzidos a partir de processos radiogênicos em rochas da crosta e reservatórios sólidos do manto, sendo denominados de terrígenos. $\mathrm{O}^{3} \mathrm{He}$ é gerado por intermédio da ação de nêutrons de Li, sendo o fluxo de nêutrons crustais resultado de reações do tipo $(\alpha, n)$ em núcleos leves (ANDREWS 1985). O ${ }^{4} \mathrm{He}$ é gerado pelo decaimento de U e Th e de seus isótopos irmãos, enquanto o isótopo ${ }^{40} \mathrm{Ar}$ e formado pela captura eletrônica de ${ }^{40} \mathrm{~K}$ (HEATON 1984).

Os fluidos originados e associados a reservatórios crustais e/ou mantélicos possuem características isotópicas de GN reveladores de feições geoquímicas importantes, especialmente a razão ${ }^{3} \mathrm{He} /{ }^{4} \mathrm{He}$. A figura 5 ilustra de forma conceitual estas diferenças no enriquecimento em ${ }^{3} \mathrm{He} e / \mathrm{ou}^{4} \mathrm{He}$

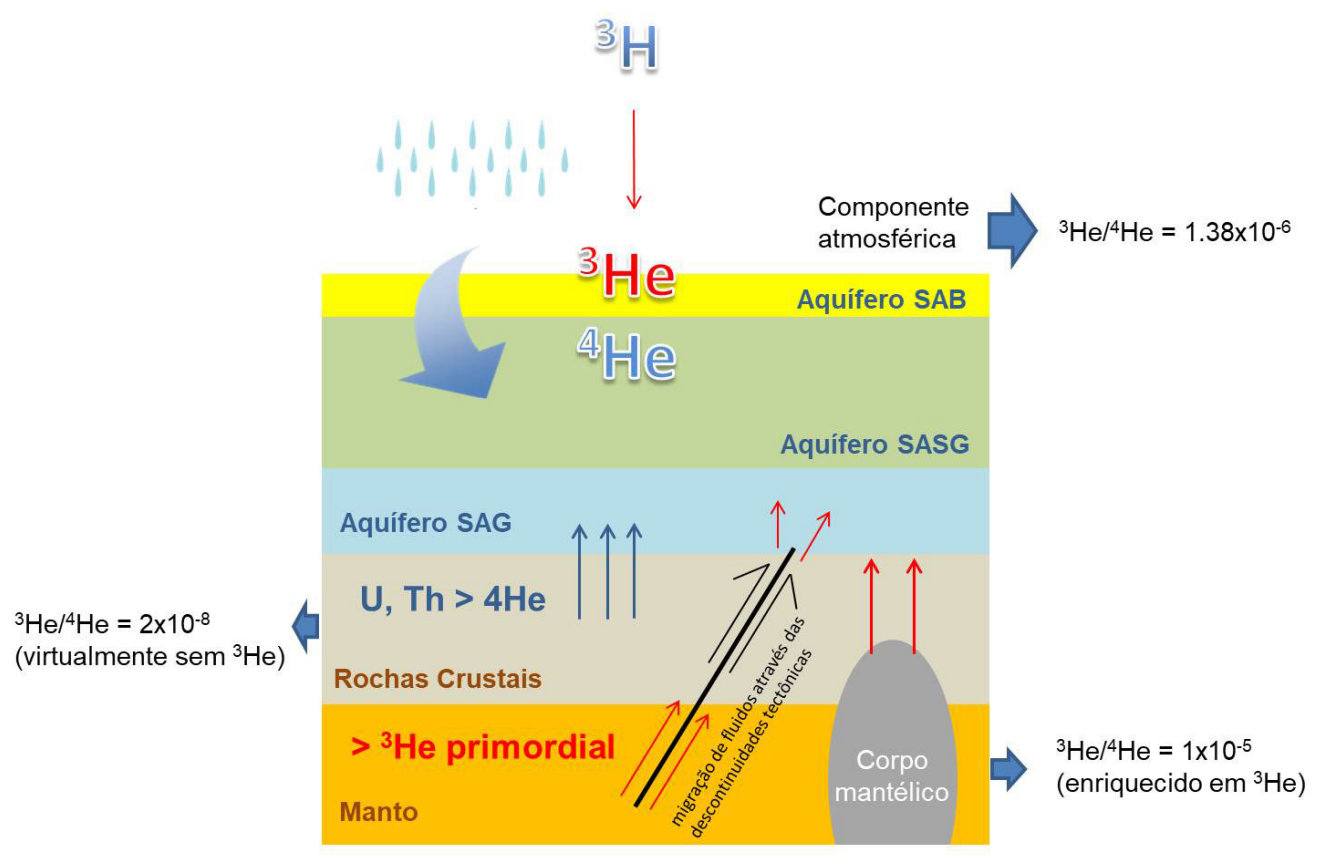

FIGURA 5 - Modelo conceitual das diferentes componentes de He e suas respectivas fontes. Modificado de MATSUMOTO (2018). 
radiogênico (com origem no manto e rochas crustais) em comparação à componente atmosférica.

A crosta continental é enriquecida isotopicamente em ${ }^{4} \mathrm{He}$, produzido in-situ por reações nucleares em rochas e minerais crustais, e apresenta razões ${ }^{3} \mathrm{He} /{ }^{4} \mathrm{He}<10^{-7}$ (MAMYRIN \& TOLSTIKHIN 1984, BALLENTINE \& BURNARD 2002). A literatura comumente refere-se a este He crustal como sendo "radiogênico".

O manto, por sua vez, contém tanto He de produção recente como também relictos de He isotopicamente enriquecido em ${ }^{3} \mathrm{He}$ ( ${ }^{3} \mathrm{He}$ primordial), herdado durante a formação do planeta, e apresenta razões ${ }^{3} \mathrm{He}{ }^{4} \mathrm{He}>10^{-5}$ (MAMYRIN \& TOLSTIKHIN 1984, PORCELLI \& BALLENTINE 2002, GRAHAM 2002), enquanto a razão atmosférica para ${ }^{3} \mathrm{He} /{ }^{4} \mathrm{He}$ é de $1,38 \times 10^{-6}$ (PINTI \& MARTY 1998). Informações mais detalhadas sobre produção e comportamento de GN no manto e na crosta podem ser encontradas em PORCELLI \& BALLENTINE (2002) e BALLENTINE \& BURNARD (2002), respectivamente.

\subsection{Separação de componentes}

A separação das componentes implica em resolver o sistema de equações imposto pela equação 1 , ilustrado pela figura 2 . As principais técnicas para proceder com a separação de componentes são: (i) usando apenas o $\mathrm{Ne}$; (ii) usando todo o conjunto de GN em abordagem iterativa; (iii) usando todo o conjunto de GN em técnicas de modelagem inversa, sendo esta considerada a mais empregada atualmente (MATSUMOTO et al. 2017).

A partir da modelagem inversa, a equação 1 pode ser reescrita como um sistema de equações explícito, ao inserir as equações descritivas da componente de equilíbrio e do excesso de ar. Restringindo o problema aos gases atmosféricos, restam equações para as componentes de equilíbrio e excesso de ar do $\mathrm{Ne}, \mathrm{Ar}, \mathrm{Kr}$ e Xe.

Os resultados obtidos pela modelagem inversa não são os componentes individuais, mas valores para os parâmetros a partir dos quais a componente de equilíbrio e a $\mathrm{C}_{\mathrm{eA}}$ podem ser calculados para todos os GN (incluindo ${ }^{3} \mathrm{He}$ e ${ }^{4} \mathrm{He}$ ). Os erros experimentais são usados como fatores com pesos garantindo que cada uma das medições individuais tem ponderação apropriada na determinação dos parâmetros finais. Além disto, o uso dos erros experimentais permite derivar estimadores objetivos para os valores dos parâmetros obtidos.

Ressalta-se, novamente, a necessidade de processar a separação das componentes, baseada no fato de que existem GN com concentrações puramente de componentes atmosféricas e devido ao excesso de ar (Equações 1 e 2, Figura 3).

Dentre as ferramentas existentes para processamento dos dados de GN, citam-se as mais conhecidas: INOBLE (PEETERS et al. 2002), PANGA (JUNG \& AESCHBACH 2018) e DGMETA (JURGENS et al. 2020).

\section{ASPECTOS METODOLÓGICOS}

Existem procedimentos específicos e aplicáveis a diferentes isótopos de GN, tanto no que se refere à amostragem como em relação às técnicas empregadas nas determinações analíticas.

\subsection{Amostragem de água subterrânea e gás}

As amostragens para $\mathrm{He}, \mathrm{Ne}, \mathrm{Ar}, \mathrm{Kr}, \mathrm{Xe}$, razões ${ }^{3} \mathrm{He} /{ }^{4} \mathrm{He}$ e ${ }^{40} \mathrm{Ar} /{ }^{36} \mathrm{Ar}$ são realizadas a partir de alíquotas de água subterrânea. Dentre os métodos utilizados nas amostragens das espécies supracitadas, os mais usuais são o aprisionamento de amostras de água em tubos de cobre e o uso de amostradores passivos (difusivos). O manual de coleta para GN desenvolvido pelo laboratório IHL-AIEA (2010) fornece uma comparação entre ambos os procedimentos.

A figura 6 ilustra os procedimentos de campo para coleta de gases nobres a partir do armazenamento de água subterrânea em tubos de cobre de 10 $\mathrm{mm}$ de diâmetro e $1 \mathrm{~mm}$ de espessura. Os tubos ficam apoiados em um suporte de alumínio com braçadeiras de aço, e nas extremidades o tubo é fixado por grampos, que são parafusados com o uso de uma chave. As braçadeiras devem ser bem apertadas/fechadas, porém com o cuidado de não provocar a quebra do tubo. O poço a ser amostrado não deve permitir troca gasosa (contato da água com o ar), sendo ideal que a água subterrânea esteja sendo extraída a uma pressão suficiente e constante sem a presença de borbulhamento e/ou desgaseificação (TORGESEN \& STUTE 2013, USGS 2019, EAWAG 2021).

As amostragens para ${ }^{81} \mathrm{Kr},{ }^{85} \mathrm{Kr}$ e ${ }^{39} \mathrm{Ar}$, por sua vez, são constituídas de alíquotas de gás obtidas por intermédio de extratores de gás. As amostragens baseadas em sistemas de extração de gás in-situ precisam atender as seguintes premissas: (i) garantir estanqueidade evitando a contaminação da amostra com o ar moderno (gases atmosféricos), (ii) operar altas taxas de extração de gás para reduzir o tempo e o volume de água amostrada e; (iii) possuir robustez e simplicidade para uso 
em condições de campo e transporte até os locais de amostragem.

Utilizam-se dois tipos de sistemas extratores de gás em campo: (a) baseados em câmaras de extração com cilindros a vácuo e, (b) baseados em contatores de membrana. Em ambos os casos, as amostras são transferidas do poço ao sistema extrator no qual se processa a filtragem das partículas maiores da água e extração e descarga do gás.

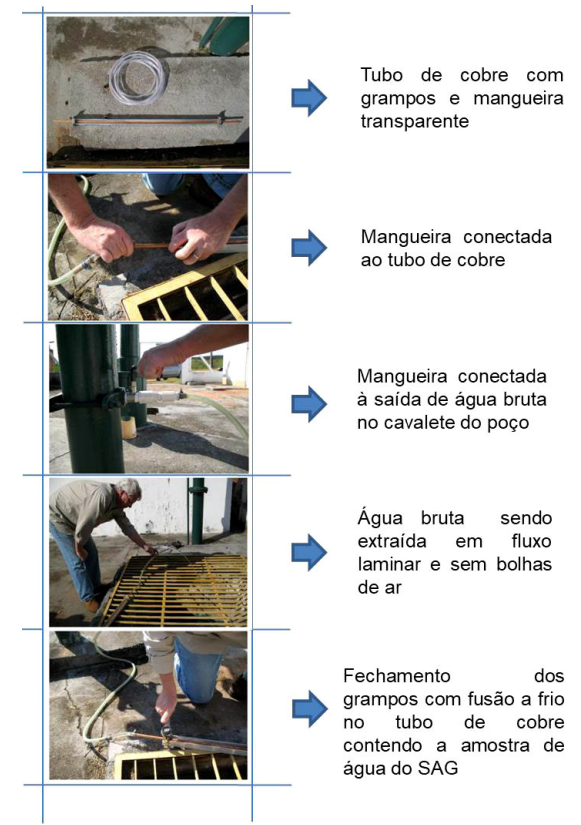

Ambos possuem o mesmo arranjo de válvulas e medidores de pressão e controle para fluxo de água e gás (PURTSCHERT et al. 2013).

A figura 7 ilustra o arranjo de campo para as extrações de gases a partir da água subterrânea. $\mathrm{O}$ protótipo extrator visualizado abaixo (EDGAR-2, construído por LEBAC-UNESP) é análogo ao modelo EDGAR (Extraction of Dissolved Gas for Analysis of Radiokrypton), originalmente de-

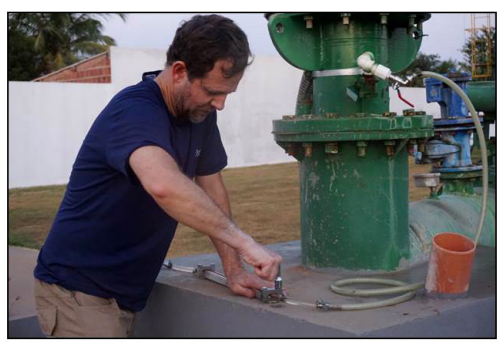

Arranjo operacional da coleta de gases nobres em Poço Tubular de SAG confinado

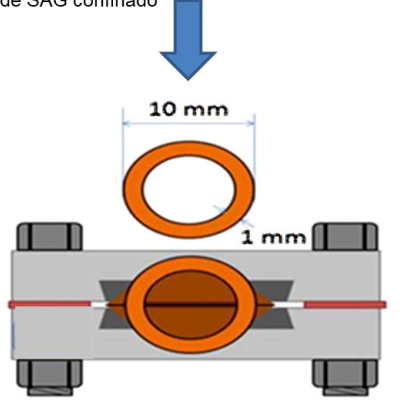

FIGURA 6 - Fluxograma dos procedimentos operacionais para a amostragem de água subterrânea para análise de GN. Extraído de KIRCHHEIM (2021). SAG: Sistema Aquífero Guarani.
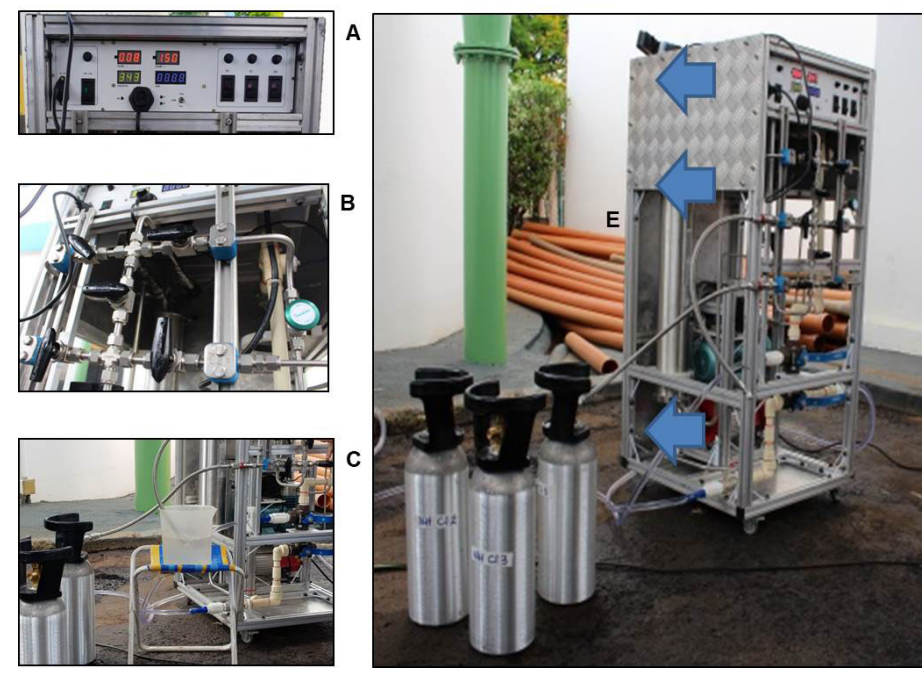
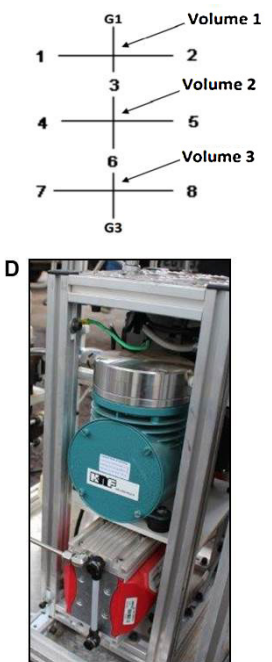

FIGURA 7 - Sistema extrator baseado em contatores de membrana (EDGAR-2) em pleno funcionamento: A - Painel de controle de temperatura e pressão, B - Sistema de válvulas; C - Saídas de água desgaseificada; D Sistema de bombas, E - Membrana contatora (Extraído de KIRCHHEIM 2021). 
senvolvido na Universidade de Illinois, Chicago (PROBST et al. 2006).

PROBST et al. (2007) demonstram a eficiência de extração de gás usando o $\mathrm{O}_{2 \text { dis }}$ como proxy antes e depois da passagem de água através da membrana a taxas de fluxo da ordem de 4 a $34 \mathrm{~L} / \mathrm{min}$.

Dentre as vantagens destacadas por PURTSCHERT et al. (2013), podem ser incluídas a disponibilidade e custo das membranas no mercado; a atuação de membranas em paralelo (permitindo maior fluxo de água subterrânea na entrada), assim como em série (aumentando a eficiência da extração); montagem em sistema robusto, compacto e de fácil transporte e operação e; a operacionalidade do sistema a diferentes taxas de fluxo. Por outro lado, o sistema com membranas apresenta alta sensibilidade à composição química e à temperatura da água subterrânea $\left(<70^{\circ} \mathrm{C}\right)$; não é apropriado na presença de substâncias que diminuam a tensão superficial da água; é sensível à presença de matéria precipitada ou em suspensão, capaz de obstruir os poros da membrana e; necessita de cuidados especiais na sua regeneração.

Atualmente, estão em desenvolvimento equipamentos com membranas contatoras menores, e que, a priori, permitem amostragens mais rápidas com menores volumes de água subterrânea bombeada e gás extraído (OHTA et al. 2009).

YOKOCHI (2016) apresenta avanços em equipamento portátil e eficiente para extração de gases dissolvidos das águas subterrâneas, para uso em campo. Constituído de dispositivos de extração e separação de $\mathrm{Kr}$ dos gases atmosféricos, o sistema enriquece o $\mathrm{Kr}$ a partir da passagem do gás da amostra através de uma coluna de carvão ativado resfriado $(138 \mathrm{~K})$, seguido por dessorção por fracionamento. O aparelho apresentou capacidade de extração de $\mathrm{Kr}$ com rendimento $>90 \%$ e pureza de $99 \%$ em 75 minutos, e 1,2 a 26,8 L de STP de ar atmosférico.

\subsection{Determinação das concentrações de GN}

Em termos analíticos, as determinações das concentrações de $\mathrm{He}, \mathrm{Ne}, \mathrm{Ar}, \mathrm{Kr}$, Xe, razões ${ }^{3} \mathrm{He} /{ }^{4} \mathrm{He}$ e ${ }^{40} \mathrm{Ar} /{ }^{36} \mathrm{Ar}$ a partir das alíquotas de água são realizadas com a utilização de espetrômetros de massa, que usualmente contam com arranjos de caráter integrado, incluindo processos automáticos de alimentação de amostras, purificação e um sistema próprio de extração de gás para a análise de GN (MATSUMOTO et al. 2017).

De acordo com AESCHBACH \& SOLOMON (2013), a determinação absoluta da concentração de um GN específico requer a comparação entre o si- nal extrapolado e os sinais de calibração de alíquotas de ar preparadas da mesma forma que as amostras por analisar. Os procedimentos analíticos fornecem sinais (correntes e ou contagens) que precisam ser convertidos em concentrações de GN por comparação com padrões conhecidos, levando em conta efeitos de não linearidade e flutuações da sensibilidade. Detalhes específicos de calibração são diferentes para cada laboratório e técnica analítica utilizada. A maior parte dos laboratórios usa diferentes tamanhos de padrões de ar para corrigir possíveis não linearidades da sensibilidade da totalidade do processo (preparação, ionização, detecção). A análise periódica de padrões conhecidos (no intuito de replicá-los) é prática desejável para manter a estabilidade de largo prazo do sistema. A estimação e quantificação destes erros são fundamentais para a estimação das TGN. Maiores informações podem ser obtidas em BURNARD et al. (2013).

BRENNWALD et al. (2016) desenvolveram espectrômetro de massa portátil (MiniRueddi) para quantificação das pressões parciais de $\mathrm{He}, \mathrm{Ne}, \mathrm{Ar}$, $\mathrm{Kr}, \mathrm{N}_{2}, \mathrm{O}_{2}, \mathrm{CO}_{2}$ e $\mathrm{CH}_{4}$ a partir de alíquotas gasosas e aquosas com incerteza analítica variando de 1 a 3 \%. A operação do equipamento não requer purificação e/ou preparação da amostra, sendo muito apto para utilização no próprio site, inclusive em locais remotos. As concentrações fornecidas por este equipamento são suficientemente robustas para ampliar a distribuição espacial e absoluta das campanhas de amostragem e predefinir alvos específicos para coletas laboratoriais de gases nobres e/ou ${ }^{81} \mathrm{Kr}$, acarretando minimização de custos.

Os procedimentos analíticos para os radioisótopos de $\mathrm{GN}^{81} \mathrm{Kr},{ }^{85} \mathrm{Kr}$ e ${ }^{39} \mathrm{Ar}$, a partir de alíquotas de gás, são distintos e encontram-se ainda em estágio de desenvolvimento e não podem ser considerados como rotina (LU et al. 2014). Os grandes fatores limitadores estão relacionados às dificuldades analíticas na determinação destes isótopos em concentrações naturais. As abundâncias isotópicas de ${ }^{81} \mathrm{Kr} / \mathrm{Kr}$, ${ }^{85} \mathrm{Kr} / \mathrm{Kr}$ são da ordem de $<10^{-11}$, fora do range dinâmico de espectrômetros convencionais de alta precisão. O valor da constante de atividade radiogênica do ${ }^{81} \mathrm{Kr}$, por sua vez, igualmente não se enquadra no espectro de sistemas normais de contadores de decaimento. Significa dizer que o referido radioisótopo requer técnicas analíticas diferenciadas. $\mathrm{O}$ quadro 1 fornece uma síntese das principais técnicas analíticas relacionadas a estes isótopos de GN.

As expectativas apontam para que as técnicas destes traçadores evoluam, tornando-as mais acessíveis, tais como as utilizadas para as análises dos 
QUADRO 1 - Características principais dos métodos analíticos utilizados para radioisótopos de gases nobres (PURTSCHERT et al. 2013). Extraído de KIRCHHEIM (2021).

\begin{tabular}{lll}
\hline \multicolumn{1}{c}{ Método } & \multicolumn{1}{c}{ Princípio básico } & \multicolumn{1}{c}{ Aplicações } \\
\hline Contador Ultrasensíveis $(L L C)$, & Detecção e contagem da energia emitida pelo decai- & LEHMANN et al. $(1985)$ \\
LOSSLI \& OESCHGER (1969) & mento radiogênico
\end{tabular}

Espectrômetro de Massa de Ressonância Ionizada (RIMS), THONNARD et al. (1987)

Espectrômetro de Massa com Acelerador (MAS), COLLON et al. (1997)

Fluorescência com trapeamento de átomos (ATTA), CHEN et al. (1999)
Excitação seletiva de átomos com pulsos de feixes de LEHMANN et al. (1991); laser

Contagem de átomos a com super-aceleração e alcance de altos níveis energéticos

COLLON et al. (2000), LEHMANN et al. (2003)

Detecção à base de fluorescência precedida de armadilha ótico-magnética

LEHMANN et al. (2003); STURCHIO et al. (2004); AESCHBACH-HERTIG(2014); AGGARWAL et al. (2015) isótopos estáveis dos GN (BEYERLE et al. 2000; YOKOCHI et al. 2008) com incremento na otimização dos procedimentos de extração em campo (YOKOCHI 2016).

O advento da tecnologia denominada de ATTA - Atom Trap Trace Analysis (CHEN et al. 1999, DU et al. 2003, JIANG et al. 2012, YANG et al. 2013) permitiu realizar medidas mais sistemáticas dos isótopos de GN radiogênicos. Reinaugurouse assim um novo ciclo de aplicações e discussões de traçadores em estudos ambientais. O ATTA é um método de contagem de átomos (concentrações da ordem de ppt e ppq) que dispõe de um processo de armadilha magneto-ótico capaz de capturar átomos do isótopo selecionado desde o centro de uma câmera de vácuo, quando os mesmos são bombardeados por feixes de laser. Um foto-sensor detecta a fluorescência induzida a laser emitida pelo átomo trapeado. A detecção da força necessária para trapear o átomo, assim como a fluorescência necessária, requer que o referido átomo difunda fótons a altas frequências $\left(\sim 10^{7} / \mathrm{s}\right)$, processo considerado medular para alcançar a seletividade atômica necessária. Esta seletividade se consuma quando a frequência do laser precisamente se equivale à frequência de ressonância da transição atômica particular (mesmo aquelas provocadas por sutis diferenças do tamanho e massa nuclear entre diferentes isótopos de um mesmo elemento).

As facilidades ATTA, funcionais no mundo no presente (em ordem cronológica de instalação), são as seguintes:

- Laboratório Nacional de Argonne, USA: Desenvolvimento pioneiro do ATTA-2 em parceria com a China (JIANG et al. 2012). Vale ressaltar que com o ATTA-2 de Argonne foram analisadas amostras específicas do SAG (AGGARWAL et al. 2012, 2015);

- Universidade de Ciência e Tecnologia, China: ATTA-3, considerado uma evolução do ATTA-2 de Argonne por possuir um esquema de captura e fluorescência em pulso, diminuindo efeitos de não linearidade (CHENG et al. 2013);

- Universidade de Heidelberg, Alemanha: Foco no desenvolvimento de um ATTA específico para medir ${ }^{39} \mathrm{Ar} / \mathrm{Ar}$ (WELTE et al. 2010);

- Universidade de Columbia, USA: Desenvolvimento de ATTA para medir ${ }^{84} \mathrm{Kr} / \mathrm{Xe}$ para fins industriais (APRILE et al. 2013);

- Universidade de Hamburg, Alemanha: Desenvolvimento de ATTA para monitorar ${ }^{85} \mathrm{Kr}$ atmosférico emitido por plantas nucleares e empregado pela AIEA como um sistema para detectar o não atendimento ao Tratado de Não Proliferação Nuclear (WINGER et al. 2005);

- Cooperação entre Universidade de Adelaide, Griffith e CSIRO em Waite, Austrália: Desenvolvimento de ATTA para pesquisas em águas subterrâneas (CSIRO 2020).

A existência de diferentes facilidades analíticas em operação permite o desenvolvimento de estudos comparativos e a verificação da confiança e da reprodutibilidade dos resultados. Como exemplo deste tipo de análise, cita-se a iniciativa de analisar 12 amostras para ${ }^{85} \mathrm{Kr} / \mathrm{Kr}$ com razões entre $10^{-}$ ${ }^{13} \mathrm{e} 10^{-10} \mathrm{em} 3$ laboratórios independentes (ATTAS da China e USA e LLC na Suíça). O resultado demonstrou existir concordância para uma faixa de 5\% de precisão (YANG et al. 2013). 


\section{IDADES DAS ÁGUAS SUBTERRÂNEAS}

A "idade" da água subterrânea pode ser definida como sendo resultado da acumulação de uma variável (idade mássica), equivalente à média do tempo de residência de cada uma das moléculas de água do sistema (TORGERSEN et al. 2013). PHILLIPS \& CASTRO (2003) entendem que a dinâmica dos sistemas de água subterrânea contempla interações complexas, irregulares e heterogêneas, agravada ainda pela possibilidade concreta, e até usual, de efeitos de misturas nas mais variadas escalas. Ao fluxo advectivo das águas subterrâneas, somam-se componentes de transporte difusivo e dispersivo, as quais colocam em dúvida a premissa de sistema fechado ou estanque, comumente adotada. Neste contexto, a estimação de idades e a predição de fluxo convertem-se em tarefas complicadas (DAVIS \& BENTLEY 1982).

A determinação dos tempos de residência pode ser realizada a partir de traçadores ambientais, neste caso, isotópicos. Em termos conceituais clássicos, o traçador, segundo KIPFER (2018), é qualquer átomo detectável em um material de sistema químico, biológico ou físico que pode ser usado para rastrear processos ambientais. Estes processos incluem determinação de origem, datação de água, taxas de recarga, mistura de massas entre águas de distintas origens, migração, degradação e transfor- mação de compostos. Transladando esta definição para as águas subterrâneas, um traçador de idade deve adentrar o sistema aquífero e acompanhar todo o processo de recarga, trânsito e descarga da água subterrânea (CLARK \& FRITZ 1997, COOK \& HERCZEG 2000). Como tal: (i) não devem estar sujeitos a processos de retardo químico em relação ao fluxo de água; (ii) deveriam estar sujeitos aos mesmos processos de dispersão mecânica e difusão molecular que as próprias moléculas de água, e; (iii) deveriam sofrer alterações de sua concentração a partir de uma função que varia no tempo (seja de decaimento ou de aumento de concentração), desde uma condição inicial conhecida até o local de coleta transcorrido um determinado tempo. A figura 8 ilustra os principais traçadores de idades e os espectros de idades aos quais se aplicam.

Em função dos tempos de residência, de acordo com CLARK (2015), as águas subterrâneas podem ser classificadas como sendo modernas (águas recarregadas de 1950 até os dias atuais), submodernas (recarregadas desde $1 \mathrm{k}$ anos até 1950), antigas (recargas de até 30k anos) e muito antigas (recargas anteriores a $30 \mathrm{k}$ anos). Notar que $1 \mathrm{k}=1.000$ anos.

Águas muito antigas são encontradas em unidades hidroestratigráficas de bacias sedimentares profundas, posicionadas entre estratos confinantes (PHILLIPS et al. 1989), posicionamento

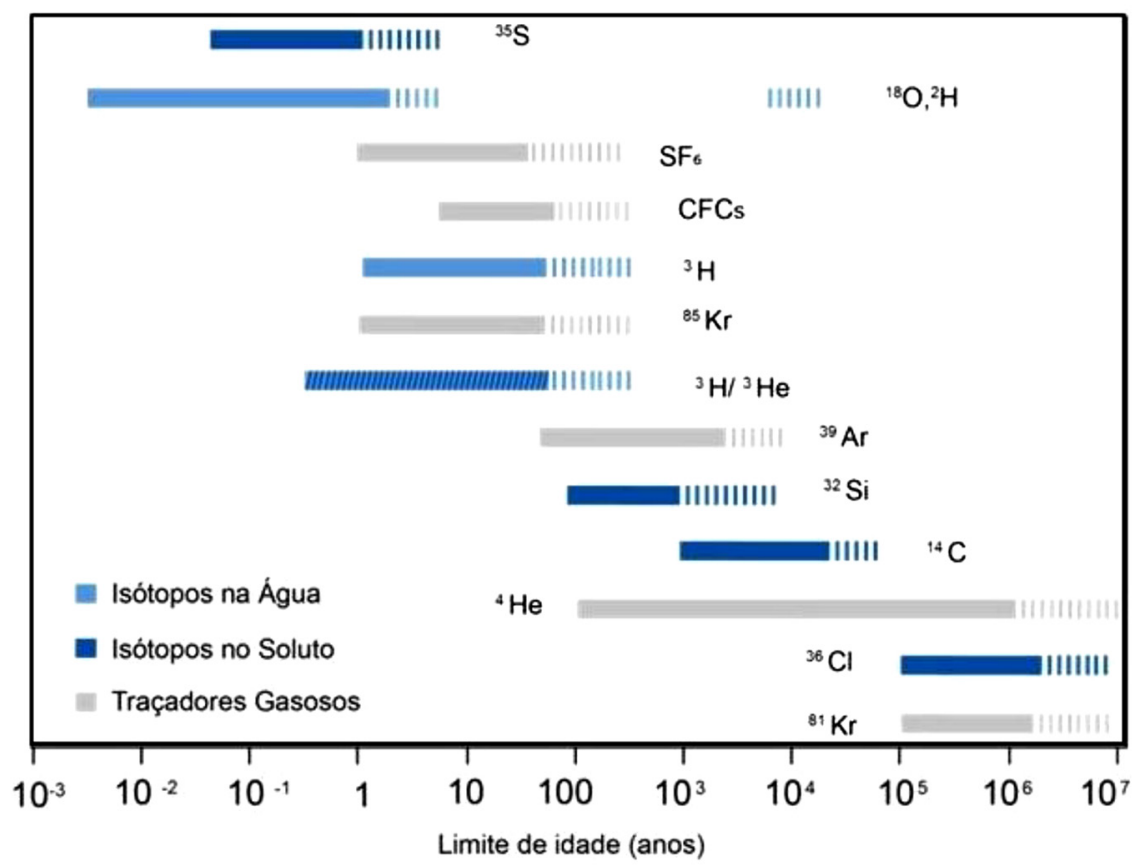

FIGURA 8 - Traçadores isotópicos e químicos usados na estimação de idades de água subterrânea. Modificado de NEWMAN et al. (2010). 
análogo para o caso de aquíferos costeiros (STUTE et al. 1992, AESCHBACH-HERTIG et al. 2002, CASTRO et al. 2007); ou em regiões áridas nas quais as recargas modernas são insuficientes para substituir as águas mais antigas, ou quando este processo é demasiado lento (STURCHIO et al. 2004, PATTERSON et al. 2005).

Segundo BALLANTINE et al. (2002), a datação de águas subterrâneas muito antigas, com idades superiores aos limites impostos pelo método ${ }^{14} \mathrm{C}$ (ou seja, em torno de 30.000 anos) pode ser realizada a partir de distintos traçadores, cada qual com desafios específicos: (i) a série de desequilíbrio do U não depende unicamente do tempo de residência da água, mas de outros parâmetros como o estado de redox da água; (ii) o emprego do ${ }^{36} \mathrm{Cl}$ cosmogênico pode tornar-se complexo em função da produção in-situ e dos valores iniciais do ${ }^{36} \mathrm{Cl}$ na matriz do aquífero; (iii) o ${ }^{4} \mathrm{He}$ apresenta taxas de acúmulo radiogênico proporcionais às idades, porém variáveis e de complexa estimação; (iv) ${ }^{8}{ }^{81} \mathrm{Kr}$ é considerado um soluto conservativo de maior simplicidade em relação a correções e interpretações, muito embora exija esforços analíticos mais complexos.

O emprego de traçadores isotópicos na mensuração dos tempos de residência em águas subterrâneas muito antigas prescinde de informações sobre os referidos isótopos: (i) conhecer quais são estes isótopos e como são formados; (ii) quais são os reservatórios destes isótopos na natureza e suas respectivas taxas de produção e transporte; (iii) quan- tificar os processos que controlam e afetam as concentrações dos isótopos no tempo nos diferentes cenários aquíferos, além de; (iv) entender de que forma estas informações podem ser comparadas e utilizadas para corroborar hipóteses e calibrar modelagens de qualidade e quantidade.

A seguir, os principais métodos cronológicos baseados em GN e seus isótopos serão descritos em maior detalhe.

\subsection{Cronômetro ${ }^{4} \mathrm{He}$}

O He, devido a sua baixa solubilidade, alta difusividade e mobilidade, acaba sendo emanado e ascende desde estratos profundos até a superfície terrestre. Este escape de He de diferentes reservatórios geoquímicos é entendido como sendo um fluxo pseudo-difusivo (O'NIONS \& OXBURGH 1988, TORGERSEN 1989). À medida que as diferentes taxas de produção de $\mathrm{He}$ (também denominadas taxas de acúmulo) possam ser estimadas (admitindo-se constância temporal destes fluxos), as concentrações de He podem fornecer interpretações mais quantitativas. Águas subterrâneas muito antigas possuem concentrações muito acima das concentrações de equilíbrio em função deste acúmulo radiogênico (ANDREWS \& LEE 1979, TORGERSEN 1980, TORGERSEN \& CLARKE 1985). Esta afirmação é ilustrada pela figura 9, que fornece os resultados das componentes parciais de amostras de água subterrânea do SAG.
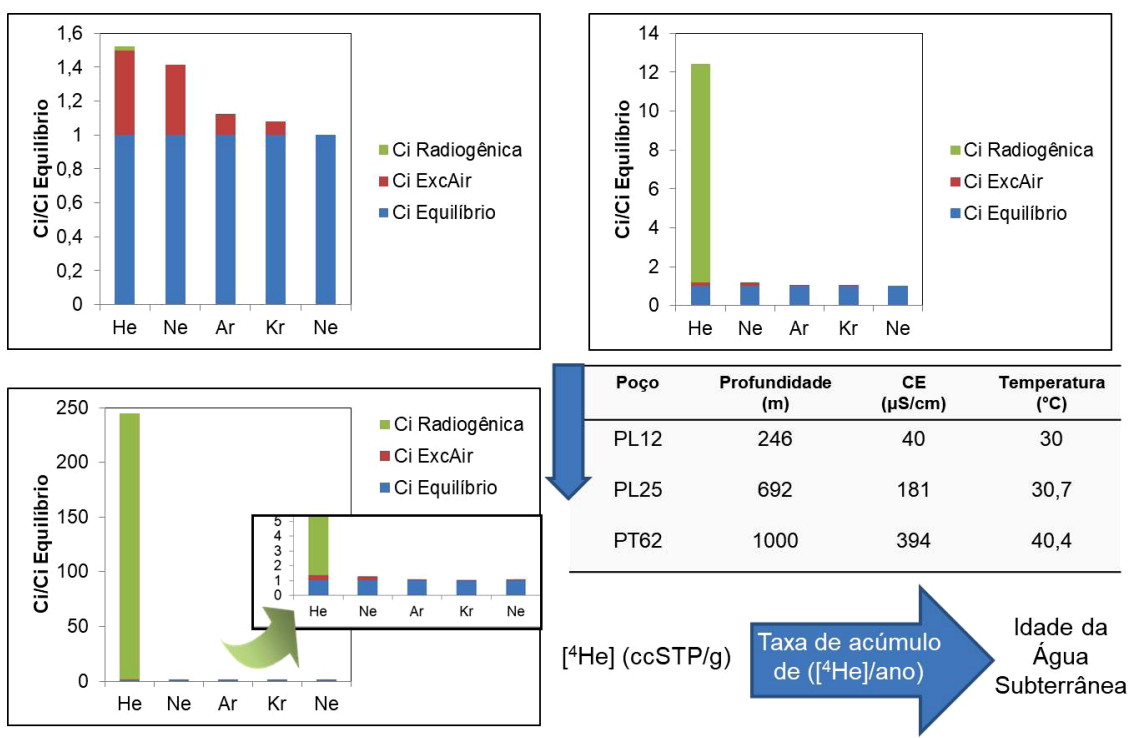

FIGURA 9 - Separação de componentes realizada com modelo CE para as amostras em SAG confinado no Brasil. As amostras foram normalizadas para a concentração de equilíbrio (100\%). Extraído de KIRCHHEIM (2021). 
O tempo de residência da água $t$ (idade da água subterrânea) é expresso pelo quociente entre a concentração radiogênica de $\left(\mathrm{He}_{\mathrm{rad}}\right)$ e a taxa de acumulação de $\mathrm{He}\left(\mathrm{JHe}_{\mathrm{ac}}\right)$ :

$$
\mathrm{t}=\left(\mathrm{He}_{\mathrm{rad}}\right) /\left(\mathrm{JHe}_{\mathrm{ac}}\right),
$$

A taxa de acumulação $\mathrm{JHe}_{\mathrm{ac}}$ não é constante e pode variar em até 3 ordens de grandeza no próprio corpo aquífero (BALLENTINE et al. 2002).

Apesar da formulação conceitual aparentemente simples, a dificuldade consiste na determinação da $\mathrm{JHe}_{\mathrm{ac}}$. Trata-se de um tema que suscita muito debate (KIPFER et al. 2002). As seguintes fontes potenciais de concentrações de $\mathrm{He}_{\mathrm{rad}}$ foram aventadas: (i) produção in situ dentro da matriz do aquífero (ANDREWS \& LEE 1979, MARINE 1979, TORGERSEN 1989); (ii) fluxo basal ( $\mathrm{JHe}_{\mathrm{b}}$ em $\mathrm{cm}^{3} \mathrm{STPcm}^{-2} \mathrm{ano}^{-1}$ ) em estado de equilíbrio oriundo de camadas adjacentes ou mesmo de toda a crosta (HEATON \& VOGEL 1979, TORGERSEN \& CLARKE 1985); (iii) difusão através de aquitardos confinantes como fonte principal de ${ }^{4} \mathrm{He}$ (ANDREWS \& LEE 1979, TOLSTIKHIN et al. 1996); (iv) disponibilização do ${ }^{4} \mathrm{He}$ a partir do intemperismo e/ou difusão de minerais da rocha matriz dos aquíferos (HEATON 1984); (v) difusão de ${ }^{4} \mathrm{He}$ a partir de sedimentos (conformando aquíferos superficiais), erodidos de rochas antigas e ricas em He (SOLOMON et al. 1996).

De forma geral, a água subterrânea incorpora simultaneamente tanto o ${ }^{4} \mathrm{He}$ produzido de forma in situ como o ${ }^{4} \mathrm{He}$ a partir de fontes externas, compondo um fluxo basal $\left(\mathrm{JHe}_{\mathrm{b}}\right)$, cuja equação (WEISE \& MOSER 1987, STUTE et al. 1992, KULONGOSKI et al. 2003) é a seguinte:

$$
\mathrm{t}=\frac{\mathrm{He}_{\mathrm{rad}}}{\left(\frac{\mathrm{JHe} \mathrm{b}}{\Phi \times \mathrm{h} \times \rho_{\mathrm{ag}}}+\mathrm{JHe} \text { in situ }\right)}
$$

Onde, $\Phi=$ porosidade do aquífero $(\%) ; \mathrm{h}=$ espessura do aquífero $(\mathrm{m})$; e $\rho_{\mathrm{ag}}=$ densidade da água $\left(\mathrm{g} / \mathrm{cm}^{3}\right)$.

A partir desta premissa, TORGERSEN \& IVEY (1985) e STUTE et al. (1992) desenvolveram modelos matemáticos que descrevem e quantificam a transferência de ${ }^{4} \mathrm{He}$ para dentro de sistemas aquíferos de comportamentos hidrodinâmicos conhecidos. Para estes autores a concentração de ${ }^{4} \mathrm{He}$ pode ser estimada em função da posição horizontal da água no aquífero, da posição da extração da água dentro do aquífero de espessura $\mathrm{h}$, supondo um fluxo basal crustal $\left(\mathrm{JHe}_{\mathrm{b}}\right)=\mathrm{FHe}$, que se converte em um fluxo efetivo $-\mathrm{FHe}_{\text {ef }}$ - à medida que atravessa o aquitardo até a base do aquífero e uma produção in situ - $\mathrm{JHe}_{\text {in situ }}$ - devido ao decaimento do U e Th.

O equacionamento proposto implica na determinação das variáveis de coeficiente hidrodinâmico de dispersão transversal (que inclui tanto a dispersão vertical expressa como função da dispersividade e a difusão expressa pelo coeficiente de difusão vertical do meio poroso) e, o fluxo efetivo de He para dentro do aquífero. O objetivo final é transformar as concentrações de ${ }^{4} \mathrm{He}_{\mathrm{rad}}$ em tempos de residência.

\subsection{Cronômetro ${ }^{81} \mathrm{Kr}$}

O método de datação com ${ }^{81} \mathrm{Kr}$ baseia-se na determinação da razão isotópica $\left({ }^{81} \mathrm{Kr} / \mathrm{Kr}\right)$. Uma vez cessadas as trocas de ar com a atmosfera durante o evento de recarga, a razão ${ }^{81} \mathrm{Kr} / \mathrm{Kr}$ decresce apenas devido ao decaimento radioativo, segundo lei exponencial, conforme o modelo conceitual da figura 9. A razão isotópica medida da amostra é expressa como sendo uma porcentagem da razão da atmosfera $100 \%$ moderna. As principais variáveis relacionadas a sua abundância e atividade no ar e na água foram determinadas por JIANG et al. (2012) e AESCHBACH-HERTIG (2014). Desde sua detecção pioneira na atmosfera (LOOSLI \& OESCHGER 1969), o ${ }^{81} \mathrm{Kr}$ tem se mostrado um excelente traçador de idades de água subterrânea, expandindo o range de idades mensuráveis através do tradicional método de ${ }^{14} \mathrm{C}$ (Figura 10). Além de não se envolver em reações químicas (outra vantagem significativa em relação aos traçadores considerados mais reativos como o ${ }^{14} \mathrm{C} \mathrm{e}{ }^{36} \mathrm{Cl}$ ), o ${ }^{81} \mathrm{Kr}$ acaba não sendo afetado por variações em suas concentrações absolutas devido à componente de excesso de ar.

A equação geral para determinação das idades é a seguinte:

$$
R^{81} K r_{\text {amostra }}=R^{81} K r_{\text {atmosfera }} \times e^{-\lambda t} \text { Eq. } 6
$$

$\mathrm{R}^{81} \mathrm{Kr}_{\text {amostra }}$ equivale à razão isotópica medida na amostra $\left({ }^{81} \mathrm{Kr} / \mathrm{Kr}\right)_{\text {amostra; }}$; ${ }^{81} \mathrm{Kr}_{\text {atmosfera }}$ equivale à razão isotópica da atmosfera $\left({ }^{81} \mathrm{Kr} / \mathrm{Kr}\right)_{\text {atmosfera; }}$; $\lambda$ é a constante de decaimento do ${ }^{81} \mathrm{Kr}=3,03 \times 10^{-6} /$ anos. Vale lembrar que sua concentração na atmosfera é considerada secularmente constante. O tempo transcorrido desde o instante que a água estava em contato com a atmosfera pode ser estimado a partir da equação 7 .

$$
t_{K r}=-\frac{1}{\lambda} \ln \left(\frac{R_{\text {amostra }}}{R_{\text {atmosfera }}}\right)
$$




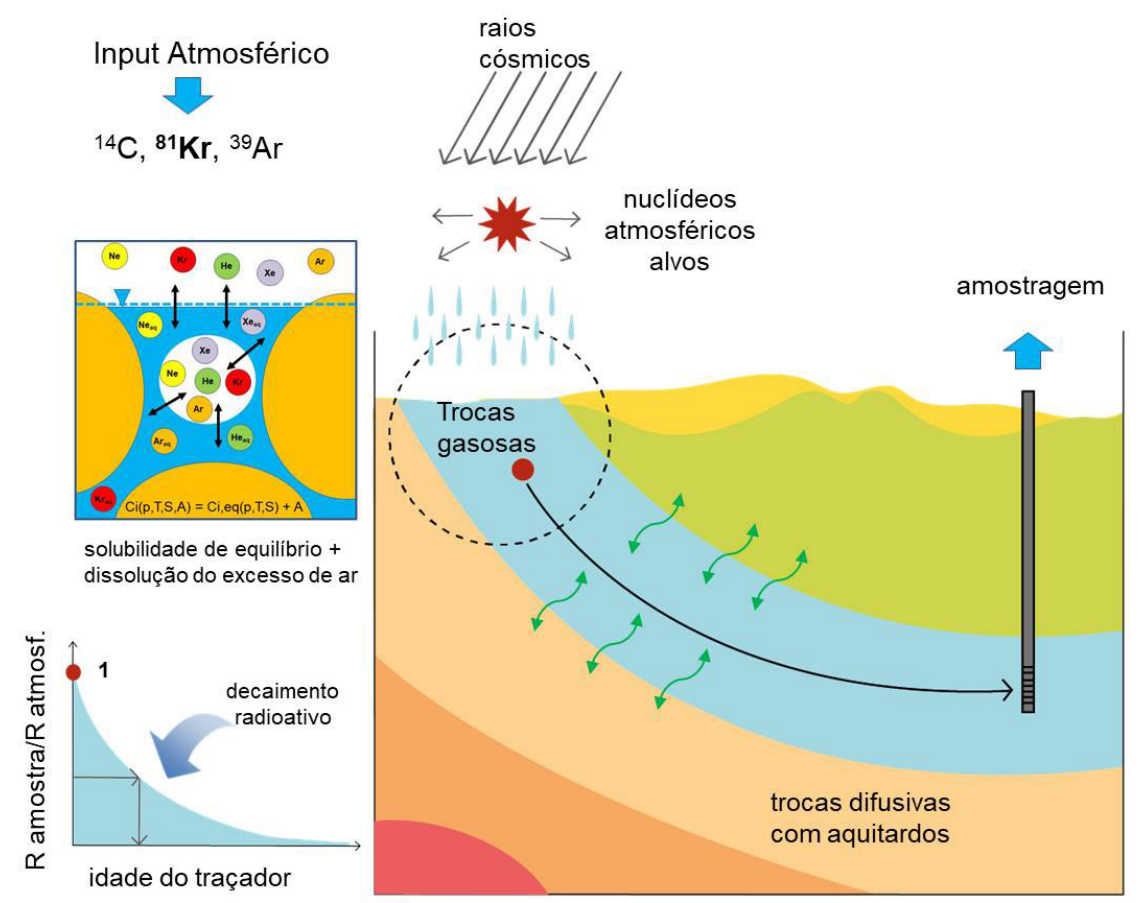

FIGURA 10 - Modelo conceitual dos processos de datação com gases nobres. Extraído de KIRCHHEIM (2021).

Dada uma razão atmosférica constante ${ }^{81} \mathrm{Kr} /$ $\mathrm{Kr}$, as razões em água subterrânea podem ser normalizadas pela razão atmosférica $\left(\mathrm{R} / \mathrm{R}_{\mathrm{ar}}\right)$, sendo então expressas como um valor em (\%) do valor inicial.

As primeiras medidas de ${ }^{81} \mathrm{Kr}$ em água subterrânea foram reportadas por LEHMANN et al. (1991) e THONNARD et al. (1997) no aquífero Milk River, Canadá. COLLON et al. (2000) usando nova técnica analítica baseada em espectrômetro de aceleração de massa acoplado a cíclotron determinou tempos de residência das águas subterrâneas no Great Artesian Basin na Austrália (GAB).

A técnica analítica ATTA (CHEN et al. 1999, DU et al. 2003) deu novo impulso ao uso dos traçadores ${ }^{81} \mathrm{Kr}$ e ${ }^{39} \mathrm{Ar}$. Esta técnica permite analisar ${ }^{81} \mathrm{Kr}$ a partir de gás extraído diretamente dos poços tubulares com expressiva redução do tamanho/volume da amostra. STURCHIO et al. (2004) em trabalho de datação das águas subterrâneas no Aquífero Nubian, do norte da África, apresentou os resultados pioneiros com o emprego dessa técnica.

\subsection{Cronômetro ${ }^{81} \mathrm{Kr}-{ }^{4} \mathrm{He}$}

A premissa fundamental inerente ao método ${ }^{81} \mathrm{Kr}-{ }^{4} \mathrm{He}$ é a de utilizar idades absolutas geradas pelo traçador ${ }^{81} \mathrm{Kr}$ para calibrar as variáveis (coeficiente hidrodinâmico de dispersão transver- sal e fluxo efetivo basal de $\mathrm{He}$ ) na equação proposta por TORGERSEN \& IVEY (1985) e STUTE et al. (1992). A calibração de fluxo basal e difusão vertical para a solução analítica do modelo do referido modelo baseia-se na otimização dos resultados a partir da comparação com idades ${ }^{81} \mathrm{Kr}$ conhecidas e minimização dos erros.

Até pouco tempo, as idades estimadas através de ${ }^{4} \mathrm{He}_{\text {rad }}$ eram calibradas usando idades obtidas por ${ }^{14} \mathrm{C}$ (PLUMMER et al. 2012). Os recentes avanços analíticos relacionados ao ${ }^{81} \mathrm{Kr}$ permitiram seu uso como uma ferramenta complementar para calibrar a funcionalidade cronométrica do ${ }^{4} \mathrm{He}$, superando assim a fronteira de idades imposta pelo método ${ }^{14} \mathrm{C}$ (LEHMANN et al. 2003, STURCHIO et al. 2004, AESCHBACH-HERTIG 2014). O método baseado em ${ }^{14} \mathrm{C}$ segue sendo muito empregado (SILVA Jr et al. 2021).

De forma pioneira, AGGARWAL et al. (2015) aplicaram a metodologia do cronômetro $\left({ }^{81} \mathrm{Kr}-{ }^{4} \mathrm{He}\right)$ na parte norte do SAG, utilizando poços representativos de idades ${ }^{81} \mathrm{Kr}$ conhecidas, ajustando as variáveis para converter concentrações de ${ }^{4} \mathrm{He}_{\text {rad }}$ nas águas subterrâneas do SAG em idades. MATSUMOTO et al. (2018) utilizaram esta aplicação em aquífero profundo de área tectonicamente ativa do norte da China (North China Plain-NCP). 
Maiores informações sobre o NCP podem ser obtidas em DONG et al. (2002) e WEI et al. (2015).

A grande vantagem inerente a esta abordagem é a possibilidade de estimar idades a partir da concentração de ${ }^{4} \mathrm{He}_{\text {rad }}$ sem a necessidade de contar com numerosas e dispendiosas determinações de ${ }^{81} \mathrm{Kr}$. Além dos custos menores, o emprego do método traz facilidades logísticas importantes.

\subsubsection{Cronômetro ${ }^{3} \mathrm{H}-{ }^{3} \mathrm{He}$ (Tritiogênico)}

$\mathrm{O}{ }^{3} \mathrm{He}$ gerado pelo decaimento do ${ }^{3} \mathrm{H}$ atmosférico (denominado de ${ }^{3} \mathrm{H}$ tritiogênico $-{ }^{3} \mathrm{H}_{\text {trit }}$ ) é usado de forma quantitativa para datar águas subterrâneas juvenis com tempos de residência de até 50 anos. Tão logo a parcela de água em questão não mais realiza trocas gasosas com o ar atmosférico, o decaimento de ${ }^{3} \mathrm{H}$ é correspondido com o consequente aumento da concentração do ${ }^{3} \mathrm{He}_{\text {trit. }}$. A razão ${ }^{3} \mathrm{He}_{\text {tri }}{ }^{3} \mathrm{H}$ aumenta com o tempo e a idade derivada pode ser obtida a partir da lei de decaimento (TOLSTIKHIN \& KAMENSKIY 1969). A constante de decaimento do ${ }^{3} \mathrm{H}$ é $\lambda_{1 / 2}=12,32$ anos (LUCAS \& UNTERWEGGER 2000). $\mathrm{O}^{3} \mathrm{H}$ é apresentado pela unidade TU (Unidades de Trítio), sendo que $1 \mathrm{TU}={ }^{3} \mathrm{H} /{ }^{1} \mathrm{H}=10^{-18}$. As principais referências deste método são TOLSTIKHIN \& KAMENSKIY (1969), SCHLOSSER et al. (1988, 1989), SOLOMON et al. (1996), COOK \& SOLOMON (1997) e HOLOCHER et al. (2001). Na presente edição, GILMORE et al. (2021) descrevem esta técnica.

\subsubsection{Cronômetro ${ }^{85} \mathrm{Kr}$}

O nuclídeo de ${ }^{85} \mathrm{Kr}$ é formado durante fissão em reatores nucleares e liberado para a atmosfera pelo reprocessamento de barras usadas de combustível nuclear (LU et al. 2014). A razão atmosférica ${ }^{85} \mathrm{Kr} / \mathrm{Kr}$ é $\sim 2 \times 10^{-11}$. Devido a sua meia vida curta (10,8 anos), sua distribuição espacial na atmosfera não é considerada uniforme (como no caso do ${ }^{39} \mathrm{Ar}$ e ${ }^{81} \mathrm{Kr}$ ). $\mathrm{O}{ }^{85} \mathrm{Kr}$ é muito útil na datação de águas juvenis de 1 a 40 anos (SMETHIE JR et al. 1992, ALTHAUS et al. 2009, MOMOSHIMA et al. 2011). Atualmente, as concentrações de ${ }^{85} \mathrm{Kr}$ podem ser medidas a partir do método de contadores ultrasensíveis (LLC) e ATTA (JIANG et al. 2012, YANG et al. 2013).

\subsubsection{Cronômetro ${ }^{39} \mathrm{Ar}$}

$\mathrm{O}{ }^{39} \mathrm{Ar}$ possui origem cosmogênica e sua razão atmosférica $\left({ }^{39} \mathrm{Ar} / \mathrm{Ar}\right.$ ) é de $8 \times 10^{-16}$ (LOOSLI 1983). Os estudos apontam para produção subsu- perficial importante, fator que precisa ser avaliado no seu uso para fins de datação, especialmente em sistemas geotermais e aquíferos fraturados formados por rochas graníticas (LEHMANN et al. 1993, MEI et al. 2010). $\mathrm{O}^{39} \mathrm{Ar}$ preenche o intervalo de estimação de idade entre o ${ }^{85} \mathrm{Kr}, \mathrm{o}{ }^{3} \mathrm{H} /{ }^{3} \mathrm{He}$ e $\mathrm{o}{ }^{14} \mathrm{C}$, tornando-o muito apto para processos ambientais de poucos milhares de anos (LOOSLI \& OESCHGER 1968, LEHMANN \& PURTSCHERT 1997). Sua meia vida é de 269 anos. Tanto as técnicas LLC e ATTA são aptas para estimar suas concentrações sendo que a última requer volumes amostrais menores (JIANG et al. 2012).

\subsection{Temperaturas de recarga}

Os GN atmosféricos dissolvidos nas águas subterrâneas (Ne, $\mathrm{Ar}, \mathrm{Kr}$ e Xe, com exceção do He, que geralmente contém componentes radiogênicos) fornecem informações sobre as condições climáticas durante a recarga. Em particular, fornecem a temperatura de recarga, também denominada de temperaturas dos gases nobres (doravante TGN) ou paleotemperaturas. A combinação das TGN, aliada às estimações de idades e, complementadas pelas análises de isótopos estáveis em águas subterrâneas, representa substrato substancial para empreender reconstruções paleoclimáticas.

A noção de que as concentrações de GN dissolvidos nas águas subterrâneas poderiam fornecer paleotemperaturas foi estabelecida por MAZOR (1972), que estudou as águas termais do vale do rio Jordão, em Israel. Os GN atmosféricos dissolvidos nestas águas termais refletiam temperaturas de recarga em condições muito mais frias, fato que levou os autores a concluir que os GN fornecem arquivos de paleoclima. Estas águas termais eram de origem meteórica e mantiveram a assinatura de GN que foi impressa durante sua recarga. ANDREWS \& LEE (1979) utilizaram registros de TGN nas águas subterrâneas do aquífero Bunter Sandstone na Inglaterra e os combinaram com datação a partir do método ${ }^{14} \mathrm{C}$, gerando idades desde o Holoceno até $35 \mathrm{k}$ anos (períodos finais da última glaciação). Este estudo é considerado clássico até o presente momento, pois definiu o chamado Último Máximo Glacial (LGM) como tendo ocorrido em 20k anos e reconheceu algumas restrições da técnica de TGN em áreas frias.

O grande desafio da aplicação da técnica de termometria a partir de GN em águas subterrâneas para reconstrução paleoclimática é demonstrar que suas concentrações refletem de fato as temperaturas no momento da recarga. Assume-se que os TGN refletem as temperaturas da zona não saturada, à pro- 
fundidade do nível freático de saturação, correspondência que foi demonstrada por RUDOLPH et al. (1984). Importantes reflexões sobre a aplicabilidade do método (composição da componente de ar nos solos, separação das componentes de $\mathrm{C}_{\mathrm{eA}}$, relações entre temperaturas do solo e do ar e efeitos de dispersão) foram discutidas por STUTE \& SCHLOSSER (1993) e, posteriormente, expandidas por STUTE \& SCHLOSSER (2000) e KIPFER et al. (2002).

A relação entre temperatura de recarga e a concentração de GN não é linear. Resulta que a mistura de águas subterrâneas, pertencentes a diferentes linhas de fluxo, não remete de forma direta a uma temperatura média de recarga. SELTZER et al. (2015) demonstram qualitativamente que o efeito de mistura é mais pronunciado nas idades do que nas temperaturas de recarga. Ainda assim, devido às incertezas associadas a eventuais efeitos de mistura, os autores propõem um range de valores possíveis para resfriamento da LGM e não um valor médio explícito.

O método da TGN foi aplicado para estimar registros de paleo-temperaturas de regiões tropicais e subtropicais em vários locais do mundo: (i) STUTE et al. (1992) no Texas, (ii) STUTE et al. (1995) no Brasil, (iii) STUTE \& TALMA (1998) na Namíbia, (iv) KULONGOSKI et al. (2004) em Botswana e (v) SELTZER et al. (2015) na Nova Zelândia.

\section{APLICAÇÕES DE GN NO BRASIL}

Conforme apresentado na Introdução, temos poucos estudos sobre GN e, até o presente momento, tampouco existem facilidades analíticas para sua determinação em território nacional.

STUTE et al. (1995) empreenderam o primeiro estudo envolvendo os GN em amostras de águas subterrâneas na Bacia do Parnaíba (aquíferos Cabeças e Serra Grande) na região semiárida do Piauí, nordeste do país. Este estudo é considerado clássico na discussão do paleoclima glacial em regiões tropicais. Além do mais, trouxe à tona o desenvolvimento do novo modelo de $\mathrm{C}_{\mathrm{e}}$, denominado como PR (Reequilíbrio Parcial com Atmosfera). Este mesmo conjunto de dados amostrados no Brasil foi reanalisado por BALLENTINE \& HALL (1999) e motivaram AESCHBACH-HERTIG et al. (2000) a definir o modelo de $\mathrm{C}_{\mathrm{eA}}$ denominado $\mathrm{CE}$.

Os dados de TGN obtidos para as amostras do estudo acima referido indicaram a existência de dois grupos distintos: i) águas com TGN médias em torno de $29,6^{\circ} \mathrm{C}$, holocênicas com idades $<10,4 \mathrm{k}$ anos, representando a transição entre o Último Máximo
Glacial (LGM) e o período interglacial presente; ii) águas com TGN médias de $24,3^{\circ} \mathrm{C}$, com idades variando de $6,9 \mathrm{k}$ a $35 \mathrm{k}$ anos, portanto, inseridas no intervalo LGM.

As TGN forneceram evidências de que o período compreendido pelo LGM foi caracterizado por temperaturas em média $5,4^{\circ} \mathrm{C}$ mais baixas que as atuais. Esta mesma variação, segundo os autores, deve ser interpretada como um resfriamento uniforme, que pode ser estendido a uma faixa de latitude $40^{\circ} \mathrm{N}$ a $40^{\circ} \mathrm{S}$ para todo o Continente da América do Sul, corroborando estudos relacionados à variação de altitude das linhas de neve (snow lines) em cadeias de montanhas tropicas e de zonas de vegetação.

Recentemente, CHATTON et al. (2016) analisaram gases nobres e isótopos nas águas subterrâneas dos aquíferos costeiros (Boa Viagem, Cabo e Beberibe) da região Metropolitana de Recife. Foram coletadas cerca de 40 amostras para análise de gases dissolvidos (incluindo GN), hidroquímica, isótopos estáveis, sendo que, parte delas, foi analisada para ${ }^{14} \mathrm{C}$. Os $\mathrm{GN}$ em específico foram analisados usando Cromatografia Gasosa com precisão analítica de $2,5 \%$ para Ar, e $10 \%$ para Ne. As TGN foram estimadas a partir da modelagem inversa tendo o modelo UA como referência para estimar as $\mathrm{C}_{\mathrm{eA}}$.

Os GN em conjunto com os demais gases dissolvidos evidenciaram diferentes assinaturas entre os distintos aquíferos estudados e facilitaram os autores a traçarem uma série de inferências sobre a dinâmica e os impactos antrópicos aos mesmos.

A combinação entre estimação dos tempos de residência, isótopos estáveis e TGN sugerem evidências paleoclimáticas da última glaciação nesta região tropical com temperaturas em torno de $8^{\circ} \mathrm{C}$ inferiores às atuais. $\mathrm{O}$ estudo também sugere que $\mathrm{o}$ gradiente de aquecimento entre $13,5 \mathrm{k}$ e $5 \mathrm{k}$ anos foi em torno de $1^{\circ} \mathrm{C} / 1 \mathrm{k}$ anos.

O uso de GN na compreensão da dinâmica do SAG inicia-se de forma incipiente com KIMMELMANN et al. (1995), que, de forma pioneira, coletou amostras para determinação das razões de ${ }^{3} \mathrm{He} /{ }^{4} \mathrm{He}$ em 2 poços profundos da porção noroeste do SAG. As razões encontradas para ${ }^{3} \mathrm{He} /{ }^{4} \mathrm{He}$ foram da ordem de $10^{-7}$ a $10^{-8}$ e motivaram a autora a comentar a respeito da inexistência de uma contribuição mantélica de $\mathrm{He}$ ao SAG. O referido estudo não adentrou em discussões sobre TGN e/ou estimação de tempos de residência.

Devido à visibilidade internacional e ao acúmulo de informações geradas principalmente no Projeto de Proteção e Uso Sustentável do Sistema 
Aquífero Guarani (PSAG), o SAG foi selecionado pela Agência Internacional de Energia Atômica (AIEA) em 2010 como alvo para aplicação de técnicas baseadas em gases nobres e seus isótopos. Esta iniciativa foi denominada de "Characterization of fossil groundwater systems using long-lived radionuclides: Complementary Isotopic Studies in the Southern, Western and Eastern Compartments of the Guarani Aquifer System - Groundwater Dating Along Defined Flow Paths", tendo o Laboratório de Estudos de Bacias (LEBAC)-UNESP como grupo acadêmico responsável pela condução da pesquisa no Brasil. Atividades análogas foram desenvolvidas no SAG em território da Argentina e Uruguai sob a liderança do grupo de pesquisadores da Universidad Nacional del Centro de la Provincia de Buenos Aires (Azul) e da Universidad Nacional del Litoral (Santa Fé), ambas na Argentina.

No âmbito desta iniciativa, uma série de poços tubulares de SAG confinado, localizados na porção norte (Estados de São Paulo e Paraná), foi amostrada para GN e, dentre estes, um grupo seleto para ${ }^{81} \mathrm{Kr}$ e ${ }^{14} \mathrm{C}$. Os GN foram analisados nos espetrômetros de massa do Laboratório da AIEA em Viena. As amostras coletadas para ${ }^{81} \mathrm{Kr}$ foram purificadas por destilação criogênica e cromatografia gasosa nas Universidades de Illinois em Chicago (USA) e Berna (Suíça) para posterior análise via técnica ATTA no Laboratório de Argonne, USA.

Os resultados, amplamente discutidos por AGGARWAL et al. $(2012,2015)$ evidenciam tempos de residência variando de água moderna até cerca de $834+/-91 \mathrm{k}$ anos, com base em ${ }^{81} \mathrm{Kr}$. No SAG confinado as concentrações de ${ }^{4} \mathrm{He}$ foram 23 três vezes maiores do que aquelas nas áreas de recarga consideradas em equilíbrio com o He atmosférico (Figura 11). As taxas de $\mathrm{Ne} / \mathrm{He}$ e ${ }^{3} \mathrm{He} /{ }^{4} \mathrm{He}$ indicaram que o He acumulado no SAG é uma mistura de origem atmosférica e crustal, sendo a componente mantélica considerada desprezível.

Foi demonstrado que para esta região do SAG a pura e simples utilização de taxas de acúmulo in situ de He gera uma superestimação de idades. Este aporte de He resulta ser demasiado pequeno e, para alcançar as ordens de magnitude observada, são requeridos aportes externos a partir da base do aquífero. Por outro lado, a consideração de um ingresso de He com base nas concentrações de U e Th crustais subestima completamente as idades geradas por ${ }^{81} \mathrm{Kr}$.

As determinações de idades através do método ${ }^{81} \mathrm{Kr}$ para amostras seletas do SAG foram utilizadas para a calibração de fluxos basais a partir da solução analítica do modelo de TORGERSEN \& IVEY
(1985). O mesmo procedimento analítico foi adotado por MATSUMOTO et al. (2018) para o Aquífero NCP. Os resultados da aplicação dos distintos métodos para estimar os tempos de residência no SAG podem ser apreciados na figura 12 .

Observa-se que a partir de uma determinada distância das áreas de recarga (cerca de $50 \mathrm{~km}$ ), as concentrações de ${ }^{14} \mathrm{C}$ remanescentes no SAG aproximam-se da assíntota do referido método. Estimativas de idades a partir da acumulação in situ de ${ }^{4} \mathrm{He}$ e a partir do cronômetro ${ }^{81} \mathrm{Kr}-{ }^{4} \mathrm{He}$ são de similar ordem de magnitude às idades de ${ }^{14} \mathrm{C}$ e ${ }^{81} \mathrm{Kr}$ em amostras de idades inferiores a 100k, basicamente amostras de poços a distâncias $<75 \mathrm{Km}$ das áreas de recarga.

As idades obtidas a partir de fluxos basais crustais claramente subdimensionam as idades obtidas pelo ${ }^{14} \mathrm{C} \mathrm{e}{ }^{81} \mathrm{Kr}$. Em amostras a distâncias $>75 \mathrm{Km}$ das áreas de recarga, geralmente com idades superiores a 100k anos, o método de acumulação in situ superdimensiona as idades obtidas a partir de ${ }^{81} \mathrm{Kr}$. Nota-se uma relativa superposição de ordens de magnitude entre as idades obtidas por ${ }^{81} \mathrm{Kr}$ e as idades modeladas com ajuste do fluxo basal e da difusão vertical. A figura 13 ilustra as proporções de concordância entre as idades fornecidas pelo ${ }^{14} \mathrm{C}$ e pelo Modelo ${ }^{4} \mathrm{He}{ }^{-81} \mathrm{Kr}$ em relação às idades absolutas de ${ }^{81} \mathrm{Kr}$ para o mesmo grupo de amostras. Vale ressaltar que as diferenças geradas pela acumulação de $\mathrm{He}$ in situ e pelo fluxo basal continental foram muito grandes. A proporção de $21 \%$ de concordância é considerada bastante satisfatória sendo de mesma ordem de magnitude que a concordância média encontrada por MATSUMOTO et al. (2018) para as amostras do NCP.

Ainda segundo AGGARWAL et al. (2015), aquíferos regionais, como o SAG, são responsáveis pela transferência de ${ }^{4} \mathrm{He}$ radiogênico produzido na crosta intermediária e superior para a atmosfera. Adotando-se uma abordagem bastante conservadora na estimação das descargas de ${ }^{4} \mathrm{He}$, cuja magnitude remonta a $7 \times 10^{-6} \mathrm{~cm}^{3} / \mathrm{g}(\mathrm{STP})$, similar ao SAG, porém com ao menos uma ordem de magnitude menor, os demais mega-aquiferos de forma conjunta, seriam responsáveis pela transferência de até $2,7 \times 10^{12} \mathrm{~cm}^{3} /$ ano (STP) ${ }^{4} \mathrm{He}$, equivalente a $53 \%$ do total perdido pela crosta continental.

O emprego de técnicas isotópicas com GN na área indicada pela figura 11 inaugurou nova e atual fase de compreensão da dinâmica do SAG. Esta mesma metodologia foi aplicada para as demais áreas confinadas do SAG em território nacional (KIRCHHEIM 2021). 

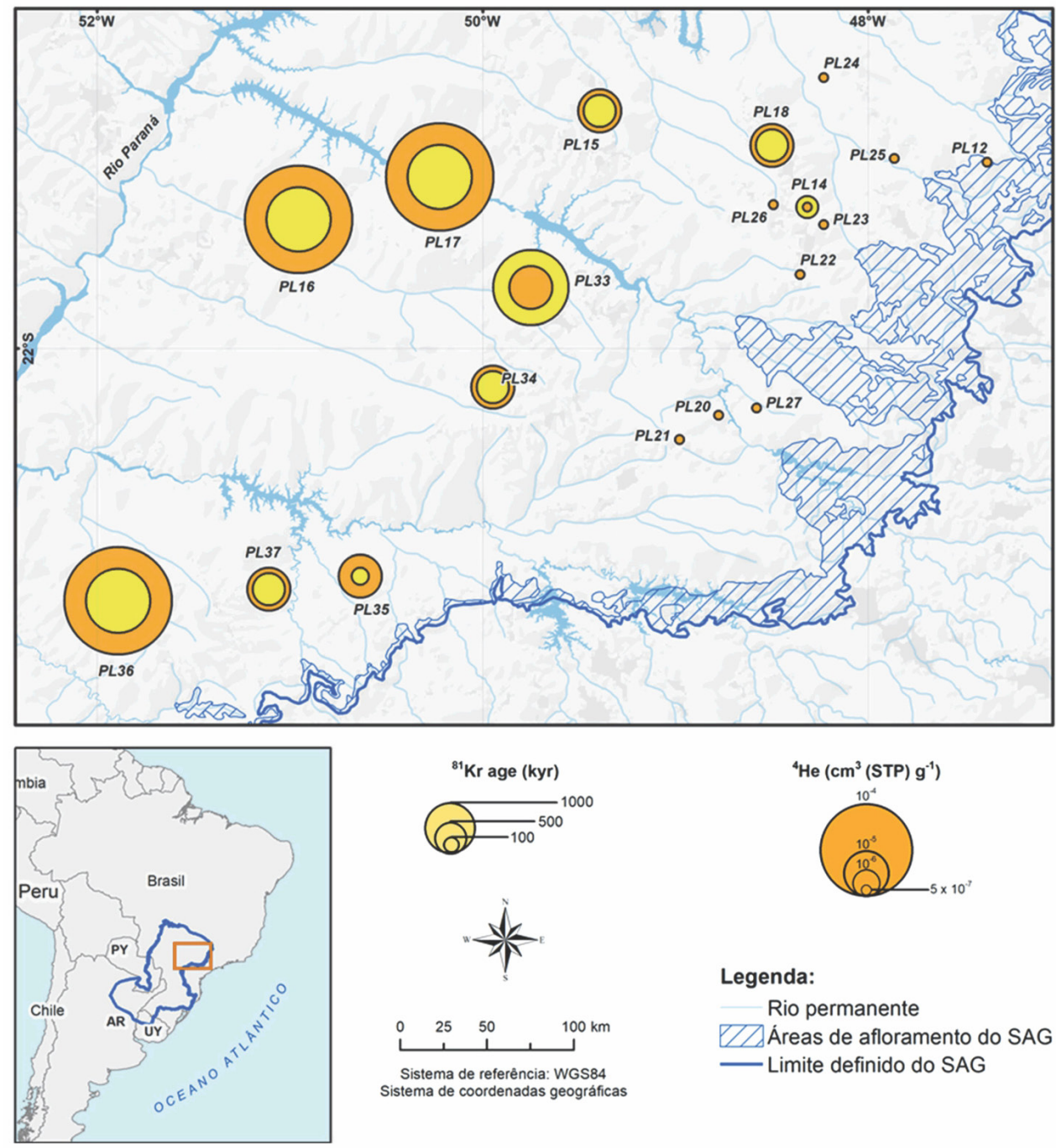

Legenda:

Rio permanente

$\square \triangle$ Áreas de afloramento do SAG

Limite definido do SAG

FIGURA 11 - Localização das amostras SAG com estimação de tempos de residência. Modificado de AGGARWAL et al. (2015).

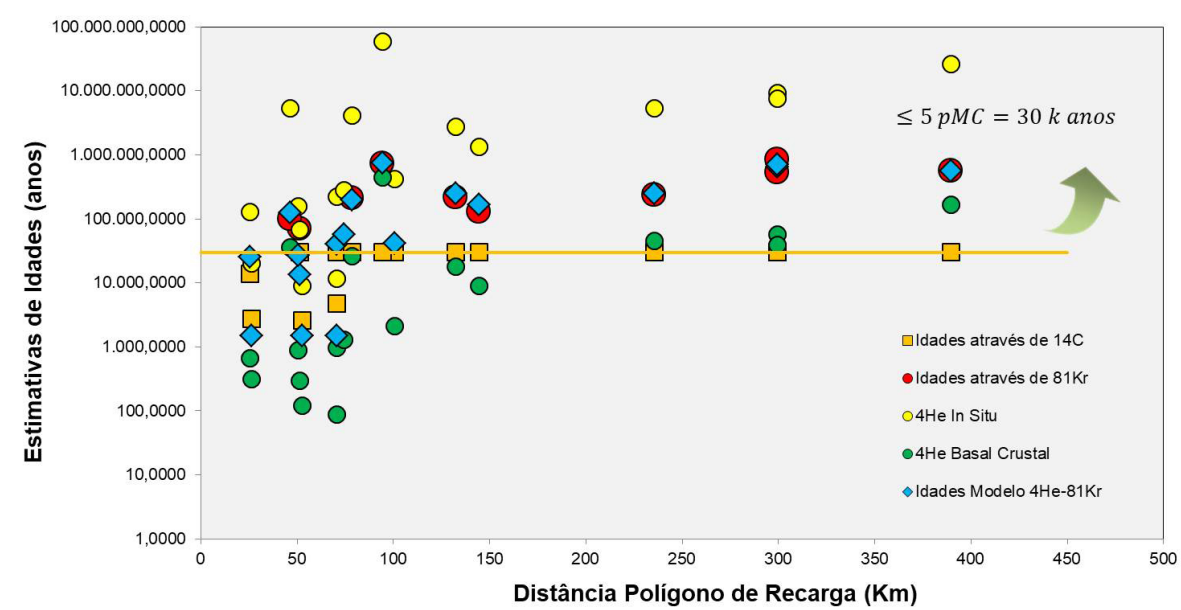

FIGURA 12 - Comparação das estimativas de idades para amostras SAG a partir dos diferentes cronômetros. Extraído de KIRCHHEIM (2021). 
Ainda com expressivo apoio da AIEA (a partir do programa denominado "Use of long-lived $\mathrm{ra}$ dionuclides for dating very old groundwaters 20172021 "), encontra-se em pleno desenvolvimento o estudo da aplicação de isótopos de GN no Sistema Aquífero Tubarão (SAT) na porção centro-leste do Estado de São Paulo. Objetiva-se aqui estimar tempos de residência e aprofundar o modelo conceitual de circulação e recarga (EZAKI et al. 2018, 2019).

O SAT constitui uma importante fonte de abastecimento de água subterrânea para uso público e privado em 47 municípios, apesar de ser considerado um aquífero de baixa produtividade, com vazões médias em torno de $10 \mathrm{~m}^{3} / \mathrm{h}$ (DAEE/IPT/IG/CPRM 2005). Em determinadas áreas, como na Região
Metropolitana de Campinas, devido ao aumento da demanda, o SAT encontra-se sob estresse hídrico (DAEE/UNESP 2013, PROFILL 2019). Conforme constatado (EZAKI et al. 2020), algumas localidades extraem águas consideradas muito antigas, idades estas determinadas a partir do método ${ }^{14} \mathrm{C}$.

Os valores de pmc obtidos indicam variação de $79,96(1,8 \mathrm{k}$ anos $)$ a $0,39(44,64 \mathrm{k}$ anos). Os resultados de ${ }^{4} \mathrm{He}$ variaram de $1,84 \times 10^{-04}$ a $7,64 \times 10^{-08} \mathrm{~cm}^{3} \mathrm{STP} / \mathrm{g}$ e demonstram correlação com os resultados de ${ }^{14} \mathrm{C}$ (Figura 14). A maioria das amostras apresenta um enriquecimento em ${ }^{4} \mathrm{He}$ de origem crustal associado ao aumento das concentrações de $\mathrm{He}_{\text {total }}$, mas algumas estão próximas do equilíbrio com a atmosfera, demonstrando ser mais jovens (Figura 15).

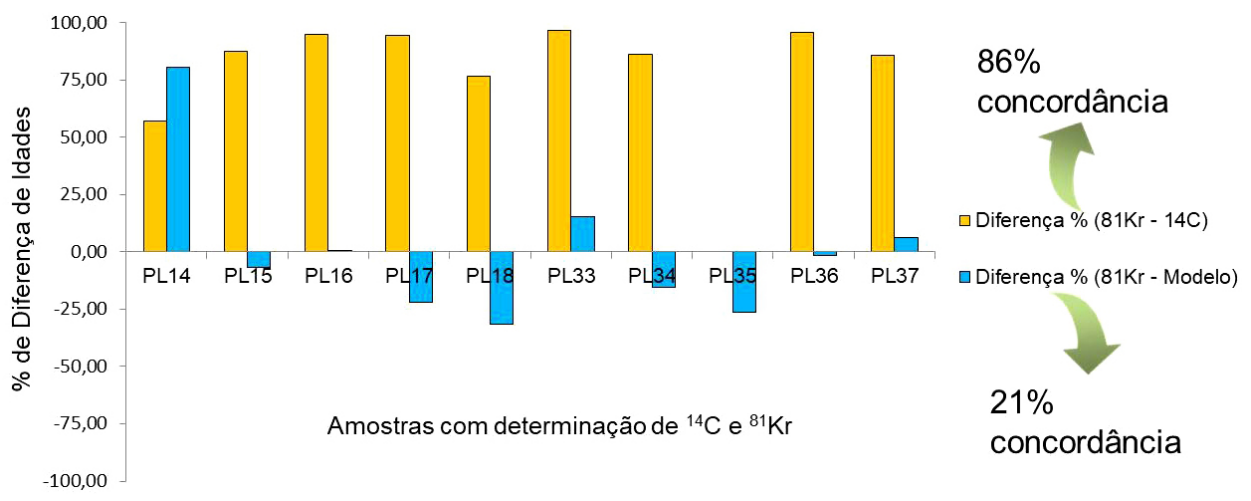

FIGURA 13 - Percentual de concordância de idades determinadas por diferentes métodos. Extraído de KIRCHHEIM (2021).

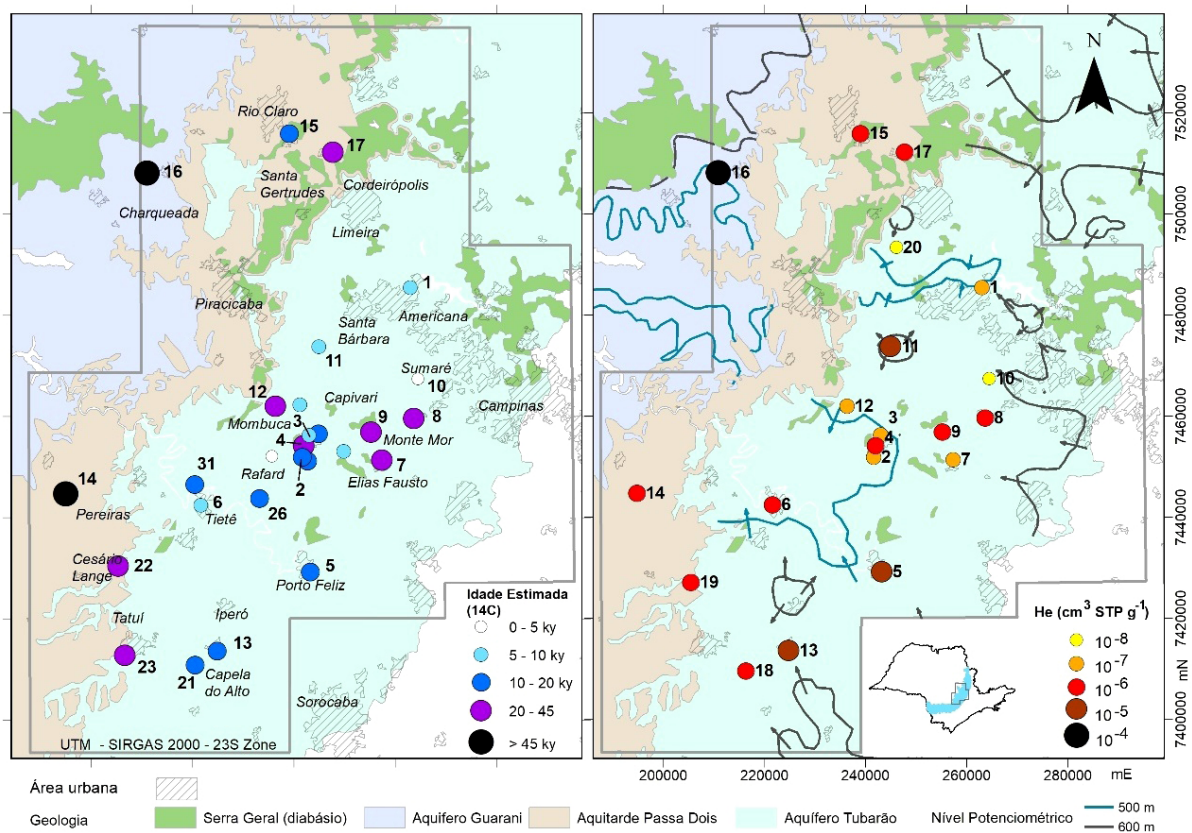

FIGURA 14 - Idades estimadas ${ }^{14} \mathrm{C}$ e concentrações de ${ }^{4} \mathrm{He}$ no Sistema Aquífero Tubarão no Estado de São Paulo. 

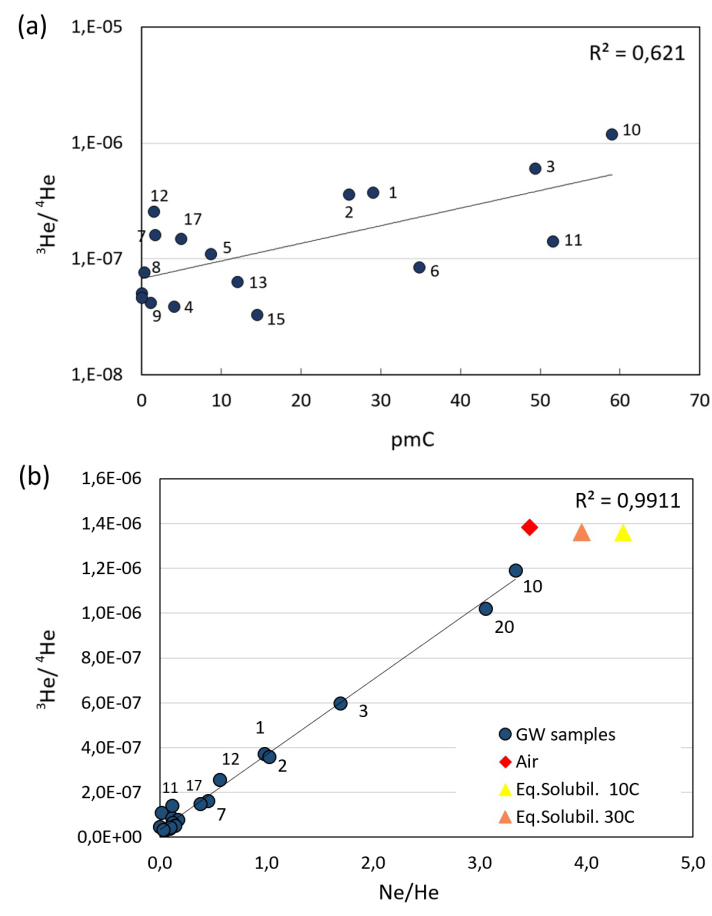

FIGURA 15 - (a) Distribuição de ${ }^{3} \mathrm{He} /{ }^{4} \mathrm{He}$ versus pmC e (b) $\mathrm{Ne} / \mathrm{He}$.

Resultados preliminares das concentrações de He demonstram a existência de correlação entre águas mais antigas em áreas confinadas (pelo Aquitarde Passa Dois) a semi-confinadas do SAT, bem como com o aumento da profundidade dos poços. As temperaturas de recarga calculadas a partir das concentrações de $\mathrm{GN}$ variam de $14,66^{\circ} \mathrm{C}$ a $30,42^{\circ} \mathrm{C}$, indicando que as recargas se processaram em períodos com clima não muito diferente do atual.

\section{CONSIDERAÇÕES FINAIS - OPORTUNIDADES E PERSPECTIVAS}

Os desenvolvimentos das técnicas associadas aos GN e seus isótopos (incluindo os radioisótopos) estenderam as possibilidades de datação de águas subterrâneas e de interpretação das mesmas como registros paleoclimáticos. É consenso na literatura especializada que a incorporação sistemática dos GN em estudos hidrogeológicos multi-paramétricos e de caráter integrado agregam sobremaneira à compreensão das dinâmicas aquíferas de fluxo. Questões fundamentais relacionadas aos GN em águas subterrâneas seguem sendo objeto de investigação, como por exemplo, os mecanismos e os fracionamentos associados às parcelas de excesso de ar, os impactos nas concentrações de GN decorrentes de misturas entre águas de diferentes aquíferos e ou aquitardos, além do entendimento das variações espaciais e temporais dos aportes difusivos crustais de He.

A baixa abundância isotópica e solubilidade em água torna complexa a tarefa analítica de detecção destes traçadores e representam (ainda) obstáculos para seu uso rotineiro em estudos ambientais. À medida que a eficiência de detecção dos novos métodos analíticos foi aumentando, os volumes amostrais puderam ser diminuídos, facilitando os aspectos logísticos das coletas.

Por outro lado, a incorporação das técnicas de GN, em virtude de seu comportamento químico inerte aos processos químicos, biológicos e de trocas água-rocha, conduz a resultados cuja interpretação é considerada menos complexa e ambígua se comparados a outros traçadores dissolvidos nas águas subterrâneas. O uso combinado de múltiplos traçadores (técnicas multitraçadores) permite maximizar e melhorar a qualidade e precisão da informação gerada. Da mesma forma, permite correlações e assiste na interpretação de dados qualitativos e quantitativos obtidos através de outros métodos.

Dentre os aspectos considerados fundamentais na aplicação das técnicas envolvendo os GN, figura a correta seleção dos poços amostrais. É imprescindível conhecer o perfil construtivo e geológico dos poços. A não adequação das perfurações e completações (no Brasil) às normas é fato corriqueiro. Idem, a busca por maximizar as entradas de água. Neste caso, poços de produção podem chegar a ter seções filtrantes em unidades aquíferas distintas. Este conhecimento prévio e o acesso a estas informações são fundamentais na seleção dos poços.

A localização espacial dos referidos poços provou ser outro fator que condiciona e muito a amplitude dos resultados e a possibilidade de contar com amplo espectro de concentrações de He. A boa representatividade dos poços selecionados para amostragem em relação às linhas de fluxo é altamente aconselhável e traz impactos importantes nos resultados.

Outro aspecto imprescindível intrínseco às técnicas diz respeito ao rigor técnico dedicado à geometria das peças do conjunto de amostragem da água para análise dos GN. É normal que os tubos de cobre disponíveis no mercado apresentem irregularidades em seus diâmetros e espessura das paredes. Idem as peças de encaixes dos parafusos que imprimem a solda fria aos referidos tubos. 
Qualquer desvio de ordem milimétrica nesta geometria pode provocar perdas de estanqueidade com consequente inutilização da amostra.

Torna-se evidente que estudos envolvendo GN e seus isótopos devem envolver engajamentos colaborativos e consórcios científicos com responsabilidades específicas. No caso do Brasil, bem como no Continente Sul-americano, esta prerrogativa torna-se ainda mais saliente. Neste sentido, destaca-se o papel indutor da AIEA no uso e difusão das referidas técnicas aplicadas à hidrogeologia.

A força tarefa envolvendo GN desenvolvida no SAG constitui exemplo a ser replicado em outros sistemas e ou unidades aquíferas no país independente da escala do estudo. As técnicas envolvendo os GN são capazes de prover idades cobrindo espectro de larga amplitude (Figura 8), desde águas juvenis $\left({ }^{3} \mathrm{H}-{ }^{3} \mathrm{He}\right)$ (GILMORE et al. 2021) até muito antigas $\left({ }^{4} \mathrm{He},{ }^{81} \mathrm{Kr},{ }^{4} \mathrm{He}-{ }^{81} \mathrm{Kr}\right)$. Águas muito antigas, com tempos de residência acima de $30 \mathrm{k}$ anos (estimadas a partir do método de ${ }^{14} \mathrm{C}$, conforme discutido em SILVA Jr et al. 2021), vêm sendo reportadas para diferentes aquíferos no Brasil. Além dos métodos já citados, novas técnicas, como por exemplo, utilizando o ${ }^{39} \mathrm{Ar}$, mostram-se altamente promissoras para satisfazer intervalos de idade e ou condições hidrogeológicas, nos quais o ${ }^{14} \mathrm{C}$ e o ${ }^{3} \mathrm{H}$ não forneçam resultados confiáveis.

\section{AGRADECIMENTOS}

Os autores gostariam de agradecer à Agência Internacional de Energia Atômica (AIEA) pelo estímulo técnico e aproximação geral com o tema, bem como pelo auxílio financeiro a partir dos Research Contracts 20957/R0 e 20812/R0, que possibilitaram os estudos nos sistemas aquíferos SAG e SAT. Não menos importantes foram os apoios institucionais e logísticos do Serviço Geológico do Brasil (CPRM-SGB), que formalmente aprovou a pesquisa com radioisótopos no SAG (do primeiro autor) no âmbito de seu Programa de Capacitação e Demanda Induzida, bem como do Instituto Geológico do Estado de São Paulo (IG-SP) e LEBAC/IGCE/UNESP em trabalhos de campo.

Finalizando, os autores agradecem aos editores da Revista do Instituto Geológico, Dr. Silvio Hiruma e aos revisores anônimos pelas excelentes sugestões e comentários oportunos, que muito contribuíram para a melhoria do manuscrito original.

\section{REFERÊNCIAS BIBLIOGRÁFICAS}

AESCHBACH, W.; SOLOMON, D.K. 2013. Noble Gas Thermometry in Groundwater Hydrology. In: P. Burnard (ed.) The Noble Gases as Geochemical Tracers. Advances in Isotope Geochemistry. Berlin Heidelberg, Springer-Verlag, p. 81-122.

AESCHBACH-HERTIG, W. 2014. Radiokrypton dating finally takes off. Proceedings of the National Academy of Sciences of the United States of America, 111(19): 6856-6857. https:// doi.org/10.1073/pnas.1405830111

AESCHBACH-HERTIG, W.; PEETERS, F.; BEYERLE, U.; KIPFER, R. 1999. Interpretation of dissolved atmospheric noble gases in natural waters. Water Resources Research, 35(9): 2779-2792. https://doi. org/10.1029/1999WR900130

AESCHBACH-HERTIG, W.; PEETERS, F.; BEYERLE, U.; KIPFER, R. 2000. Palaeotemperature reconstruction from noble gases in ground water taking into account equilibration with entrapped air. Nature, 405: 1040-1044. https://doi.org/10.1038/35016542

AESCHBACH-HERTIG,W.; STUTE,M.;CLARK, J.F.; REUTER, R.F.; SCHLOSSER, P. 2002. A paleotemperature record derived from dissolved noble gases in groundwater of the Aquia Aquifer (Maryland, USA). Geochimica et Cosmochimica Acta, 66(5): 797-817. https://doi.org/10.1016/S00167037(01)00804-3

AGGARWAL, P.K.; CHANG, H.K.; GASTMANS, D.; STURCHIO, N.C.; ARAGUAS, L.; MATSUMOTO, T.; LU, Z.; JIANG, W.; YOKOCHI, R.; MUELLER, P. 2012. Krypton-81, helium-4 and carbon-14 based estimation of groundwater ages in the Guarani Aquifer system: implications for the He-4 geochronometer. In: FALL MEETING OF AGU, Scientific program, ID: 1503002.

AGGARWAL, P.; MATSUMOTO, T.; STURCHIO, N.C.; CHANG, H.K.; GASTMANS, D.; ARAGUAS-ARAGUAS, L.J.; JIANG, W.; LU, Z.T.; MUELLER, P.; YOKOCHI, R.; PURTSCHERT, R.; TORGERSEN, T. 2015. Continental degassing of $4 \mathrm{He}$ by surficial discharge of deep groundwater. Nature 
Geoscience, 8: 35-39. https://doi.org/10.1038/ ngeo2302

ALTHAUS, R.; KLUMP, S.; ONNIS, A.; KIPFER, R.; PURTSCHERT, R.; SATUFFER, R.; KINZELBACH, W. 2009. Noble gas tracers for characterization of flow dynamics and origin of groundwater: A case study in Switzerland. Journal of Hydrology, 370(1-4): 64-72. https://doi.org/10.1016/j. jhydrol.2009.02.053

ANDREWS, J.N. 1985. The isotopic composition of radiogenic helium and its use to study ground-water movement in confined aquifers. Chemical Geology, 49(1-3): 339-351. https:// doi.org/10.1016/0009-2541(85)90166-4

ANDREWS, J.N.; LEE, D.J. 1979. Inert gases in ground water from the Bunter Sandstone of England as indicators of age and palaeoclimatic trends. Journal of Hydrology, 41(3-4): 233-252. https://doi.org/10.1016/00221694(79)90064-7

APRILE, E.; YOON, T.; LOOSE, A.; GOETZKE, L.W.; ZELEVINSKY, T. 2013. An atom trap trace analysis system for measuring krypton contamination in xenon dark matter detectors. Review of Scientific Instruments, 84: 093105. http://dx.doi.org/10.1063/1.4821879

BALLENTINE，C.J.; BURNARD， P.G. 2002. Production, release and transport of noble gases in the continental crust. Reviews in Mineralogy and Geochemistry, 47(1): 481538. https://doi.org/10.2138/rmg.2002.47.12

BALLENTINE， C.J.; HALL， C.M. 1999. Determining paleotemperature and other variables by using an error-weighted, nonlinear inversion of noble gas concentrations in water. Geochimica et Cosmochimica Acta, 63(16): 2315-2336. https://doi.org/10.1016/S00167037(99)00131-3

BALLENTINE, C.J.; BURGESS, R.; MARTY, B. 2002. Tracing fluid origin, transport and interaction in the curst. Reviews in Mineralogy and Geochemistry, 47(1): 539-614. https://doi. org/10.2138/rmg.2002.47.13

BETHKE, C.M.; JOHNSON, T.M. 2008. Groundwater Age and Groundwater Age Dating. Annual Review of Earth and
Planetary Sciences, 36: 121-52. https://www. annualreviews.org/doi/10.1146/annurev. earth.36.031207.124210

BEYERLE, U.R.S.; AESCHBACH-HERTIG, W.; IMBODEN, D.M.; BAUR, H.; GRAF, T.; KIPFER, R. 2000. A mass spectrometric system for the analysis of noble gases and tritium from water samples and Tritium from Water Samples. Environmental Science \& Technology, 34(10): 2042-2050. https://doi. org/10.1021/es990840h

BRENNWALD, M.S.; SCHMIDT, M.; OSER, J.; KIPFER, R. 2016. A Portable and Autonomous Mass Spectrometric System for On-Site Environmental Gas Analysis. Environmental Science and Technology, 50(24): 13455-13463. https://doi.org/10.1021/ acs.est.6b03669

BURNARD, P.; ZIMMERMANN, L.; SANO, Y. (eds). 2013. The Noble Gases as Geochemical Tracers. Advances in Isotope Geochemistry. Springer-Verlag, Berlin, Heidelberg, 391 p.

CASTRO, M.C.; GOBLET, P. 2005. Calculation of ground-water age - A comparative analysis. Ground Water, 43(3): 368-380. https://doi. org/10.1111/j.1745-6584.2005.0046.x

CASTRO, M.C.; HALL, C.M.; PATRIARCHE, D.; GOBLET, P.; ELLIS, B.R. 2007. A new noble gas palaeoclimate record in Texas - Basic assumptions revisited. Earth and Planetary Science Letters, 257(1-2): 170-187. https://doi. org/10.1016/j.epsl.2007.02.030

CHATTON, E.; AQUILINA, L.; PÉTELETGIRAUD, E.; CARY, L.; BERTRAND, G.; LABASQUE, T.; HIRATA, R.; MARTINS, V.; MONTENEGRO, S.; VERGNAUD, V.; AUROUET, A.; KLOPPMANN, W.; PAUWELS, H. 2016. Glacial recharge, salinization and anthropogenic contamination in the coastal aquifers of Recife (Brazil). Science of The Total Environment, 569570: 1114-1125. https://doi.org/10.1016/j. scitotenv.2016.06.180

CHEN, C.Y.; LI, Y.M.; BAILEY, K.; O’CONNOR, T.P.; YOUNG,L.;LU,Z.-T. 1999.Ultrasensitive isotope trace analyses with a magneto-optical trap. Science, 286(5442): 1139-1141. https:// doi.org/10.1126/science.286.5442.1139 
CHENG, C.-F.; YANG, G.M.; JIANG, W.; SUN, Y.R.; TU, L.Y.; HU, S.M. 2013. Normalization of the single atom counting rate in an atom trap. Optics Letters, 38(1): 31-33. https://doi. org/10.1364/OL.38.000031

CLARK, I.D. 2015. Groundwater Geochemistry and Isotopes. CRC Press, Boca Raton, 438 p.

CLARK, I.D.; FRITZ, P. 1997. Environmental isotopes in hydrogeology. CRC Press, Boca Raton, 342 p.

CLEVER, H.L. (ed). 1979a. Helium and neon gas solubilities. International Union of Pure and Applied Chemistry. Solubility Data Series, vol. 1, Pergamon Press, Oxford, 393 p. Disponível em https:/iupac.github.io/ SolubilityDataSeries/volumes/SDS-1.pdf

CLEVER, H.L. (ed). 1979b. Krypton, xenon and radon - gas solubilities. International Union of Pure and Applied Chemistry. Solubility Data Series, vol. 2, Pergamon Press, Oxford, 357 p. Disponível em https://iupac.github.io/ SolubilityDataSeries/volumes/SDS-2.pdf

CLEVER, H.L. (ed). 1980. Argon. International Union of Pure and Applied Chemistry. Solubility Data Series, vol. 4, Pergamon Press, Oxford, 331 p. Disponível em https://srdata. nist.gov/solubility/IUPAC/SDS-4/SDS-4.pdf

COLLON, P.; ANTAYA, T.; DAVIDS, B.; FAUERBACH, M.; HARKEWICZ, R.; HELLSTROM, M.; KUTSCHERA, W.; MORRISSEY, D.; PARDO, R.; PAUL, M.; SHERRILL, B.; STEINER, M. 1997. Measurement of ${ }^{81} \mathrm{Kr}$ in the atmosphere. Nuclear Instruments and Methods in Physics Research Section B, 123(1-4): 122-127. https:// doi.org/10.1016/S0168-583X(96)00674-X

COLLON, P.; KUTSCHERA, W.; LOOSLI, H.H.; LEHMANN, B.E.; PURTSCHERT, R.; LOVE, A.; SAMPSON, L.; ANTHONY, D.; COLE, D.; DAVIDS, B.; MORRISSEY, D.J.; SHERRILL, B.M.; STEINER, M.; PARDO, R.C.; PAUL, M. 2000. ${ }^{81} \mathrm{Kr}$ in the Great Artesian Basin, Australia: a new method for dating very old ground water. Earth and Planetary Science Letters, 182(1): 103-113. https://doi.org/10.1016/S0012821X(00)00234-X
CONICELLI, B.P.; HIRATA, R.; GALVÃO, P.; ARANDA. N.; TERADA, R.; GUTIÉRREZ, O.J.E. 2021. Groundwater governance: The illegality of exploitation and ways to minimize the problem. Anais da Academia Brasileira de Ciências, 93(1): e20200623. https://doi. org/10.1590/0001-3765202120200623

COOK, P. 2020. Introduction to Isotopes and Environmental Tracers as Indicators of Groundwater Flow. Published in The Groundwater Project, Guelph, Ontario, 74 p.

COOK, P.G.; HERCZEG, A.L. (eds). 2000. Environmental tracers in subsurface hydrology. Kluwer Academic Publishers, Boston, 529 p. https://doi.org/10.1007/978-14615-4557-6

COOK, P.G.; SOLOMON, D.K. 1997. Recent advances in dating young groundwater: chlorofluorocarbons, ${ }^{3} \mathrm{H} /{ }^{3} \mathrm{He}$ and ${ }^{85} \mathrm{Kr}$.Journal of Hydrology, 191(1-4): 245-265. https://doi. org/10.1016/S0022-1694(96)03051-X

CSIRO - COMMONWEALTH SCIENTIFIC AND INDUSTRIAL RESEARCH ORGANISATION. 2020. Noble Gas and ATTA Facilities. https://www.csiro.au/en/ research/natural-environment/water/noblegas-facilities

DAEE/IG/IPT/CPRM - DEPARTAMENTO DE ÁGUAS E ENERGIA ELÉTRICA/ INSTITUTO GEOLÓGICO/INSTITUTO DE PESQUISAS TECNOLÓGICAS DO ESTADO DE SÃO PAULO/SERVIÇO GEOLÓGICO DO BRASIL. 2005. Mapa de Águas Subterrâneas do Estado de São Paulo. Escala 1:1.000.000. Nota explicativa. São Paulo: DAEE - Departamento de Águas e Energia Elétrica, IG - Instituto Geológico, IPT - Instituto de Pesquisas Tecnológicas, CPRM - Serviço Geológico do Brasil, 3 v. (mapa e CD-ROM).

DAEE/UNESP - DEPARTAMENTO DE ÁGUAS E ENERGIA ELÉTRICA/UNIVERSIDADE ESTADUAL PAULISTA. 2013. Águas Subterrâneas no Estado de São Paulo. Diretrizes de Utilização e Proteção. São Paulo, DAEE/LEBAC, 44 p.

DAVIS, S.N.; BENTLEY, H.W. 1982. Dating groundwater: A short review. In: L.A. 
Currie (ed). Nuclear and Chemical Dating Techniques, Interpreting the Environmental Record. American Chemical Society, Washington.

DONG, Y.; HE, M.; JIANG, S.; WU, S.; JIANG, S. 2002. Chloride-36 age study for deep groundwater of Quaternary sediments, Hebei Plain. Earth Science - Journal of China University of Geosciences, 27(1): 105-109.

DU, X.; PURTSCHERT, R.; BAILEY, K.; LEHMANN, B.E.; LORENZO, R.; LU, Z.-T.; MUELLER, P.; O'CONNOR, T.P.; STURCHIO, N.C.; YOUNG, L. 2003. A new method of measuring ${ }^{81} \mathrm{Kr}$ and ${ }^{85} \mathrm{Kr}$ abundances in environmental samples. Geophysical Research Letters, 30(20): 2068. https://doi.org/10.1029/2003GL018293

EAWAG - SWISS FEDERAL INSTITUTE OF AQUATIC SCIENCE AND TECHNOLOGY. 2021. Guidelines for external projects. Disponível em: https://www.eawag.ch/en/ department/wut/main-focus/environmentalisotopes/noble-gas/. Acessado em jan. 2021.

EZAKI; S.; IRITANI, M.A.; GASTMANS, D.; STRADIOTO, M.R.; CHANG, H.K. 2018. Isótopos de ${ }^{14} \mathrm{C}$ e ${ }^{4} \mathrm{He}$ na Datação das Águas Subterrâneas do Aquífero Tubarão, Porção Central da Bacia do Paraná no Estado de São Paulo. In: ABAS, CONGRESSO BRASILEIRO DE ÁGUAS SUBTERRÂNEAS, 20, Campinas, Anais, 5 p.

EZAKI; S.; IRITANI, M.A.; GASTMANS, D.; MATSUMOTO, T. 2019. 14C and4He Isotopes for the Groundwater Dating of the Tubarão Aquifer System, Central Portion of the Paraná Basin in the State of São Paulo, Brazil. In: IAEA, INTERNATIONALSYMPOSIUM ONISOTOPEHYDROLOGY:ADVANCING THE UNDERSTANDING OF WATER CYCLE PROCESSES, 15, Vienna, $2 \mathrm{p}$.

EZAKI, S.; GASTMANS, D.; IRITANI, M.A.; SANTOS, V.; STRADIOTO, M.R. 2020. Geochemical evolution, residence times and recharge conditions of the multilayered Tubarão aquifer system (State of São Paulo - Brazil) as indicated by hydrochemical, stable isotope and ${ }^{14} \mathrm{C}$ data. Isotopes in Environmental and Health Studies, 27: 1-18. https://doi.org/10.1080/10256 016.2020.1797714
FAMIGLIETTI, J.S.; FERGUSON, G. 2021. The hidden crisis beneath our feet. Disappearing groundwater requires action to prevent widespread water scarcity. Science, 372(6540): 444-345. https://doi.org/10.1126/ science.abh 2867

GILMORE, T.; CHERRY, M.; GASTMANS, D. 2021. The ${ }^{3} \mathrm{H} /{ }^{3} \mathrm{He}$ Groundwater Age-Dating Method and Applications. Derbyana, 42: e743.

GRAHAM, D.W. 2002. Noble gas isotope geochemistry of mid-ocean ridge and ocean island basalts; characterization of mantle source reservoirs. Reviews in Mineralogy and Geochemistry. 47(1): 247-317. https://doi. org/10.2138/rmg.2002.47.8

HALL, C.M.; CASTRO, M.C.; LOHMANN, K.C.; MA, L. 2005. Noble gases and stable isotopes in a shallow aquifer in southern Michigan: Implications for noble gas paleotemperature reconstructions for cool climates. Geophysical Research Letter, 32(18): L18404. https://doi. org/10.1029/2005GL023582

HEATON, T.H.E. 1984. Rates and sources of ${ }^{4} \mathrm{He}$ accumulation in ground water. Hydrological Sciences Journal, 29(1): 29-47. https://doi. org/10.1080/02626668409490920

HEATON, T.H.E.; VOGEL, J.C. 1979. Gas concentrations and ages of ground waters in Beaufort Group sediments, South Africa. Water SA, 5(4): 160-170.

HEATON, T.H.E.; VOGEL, J.C. 1981. "Excess air" in groundwater. Journal of Hydrolology, 50: 201-216. https://doi.org/10.1016/00221694(81)90070-6

HOLOCHER, J.; MATTA, V.; AESCHBACHHERTIG, W.; BEYERLE, U.; HOFER, M.; PEETERS, F.; KIPFER, R. 2001. Noble gas and major element constraints on the water dynamics in an alpine floodplain. Ground Water, 39(6): 841-852. https://doi. org/10.1111/j.1745-6584.2001.tb02472.x

IHL-AIEA. Isotope Hydrology Laboratory. 2010. https://www.iaea.org/topics/water-resourcemanagement

JASECHKO, S.; PERRONE, D. 2021. Global groundwater wells at risk of running dry. 
Science, 372 (6540): 418-421. https://doi. org/10.1126/science.abc2755

JIANG, W.; BAILEY, K.; LU, Z.-T.; MUELLER, P.; O'CONNOR, T.; CHENG, C.F.; HU, S.M.; PURTSCHERT, R.; STURCHIO, N.; SUN, Y.; WILLIAMS, W.; YANG, G.-M. 2012. ATTA-3: an atom counter for measuring ${ }^{81} \mathrm{Kr}$ and ${ }^{85} \mathrm{Kr}$ in environmental samples. Geochimica et Cosmochimica Acta, 91: 1-6. https://doi.org/10.1016/j.gca.2012.05.019

JUNG, M.; AESCHBACH, W. 2018. A new software tool for the analysis of noble gas data sets from (ground)water. Environmental Modelling \& Software, 103: 120-130. https:// doi.org/10.1016/j.envsoft.2018.02.004

JURGENS， B.C.; BÖHLKE， J.; HAASE，K.; BUSENBERG, E.; HUNT, A.G.; HANSEN, J.A. 2020. DGMETA (version 1)-Dissolved gas modeling and environmental tracer analysis computer program. U.S. Geological Survey Techniques and Methods 4-F5, $50 \mathrm{p}$., https://doi.org/10.3133/tm4F5

KIMMELMANN, A.; FORSTER, M.; COELHO, R. 1995. Environmental isotope and hydrogeochemical investigation of Bauru and Botucatu aquifers, Paraná Basin, Brazil. In: IAEA (org.) Estudios de Hidrogeologia Isotópica en America Latina, 1994, IAEA, Vienna, p. 57-74 (Tech. Doc 835).

KIPFER, R. 2018. Training Course on the Use of Noble Gases in Hydrologial Studies. International Atomic Energy Agency (IAEA), Vienna.

KIPFER， R.; AESCHBACH-HERTIG， W.; PETERS, F.; STUTE, M. 2002. Noble gases in lakes and ground water. Reviews in Mineralogy \& Geochemistry, 47(1): 615-700.

KIRCHHEIM, R.E. 2021. Hidrodinâmica e Estudos Isotópicos Complementares no Sistema Aquifero Guarani (Brasil) - Datação ao longo das linhas de fluxo. Instituto de Geociências e Ciências Exatas, UNESP, Rio Claro, Tese de Doutorado.

KULONGOSKI, J.T.; HILTON, D.R.; IZBICKI, J.A. 2003. Helium isotope studies in the Mojave Desert, California: implications for groundwater chronology and regional seismicity. Chemical Geology, 202(12): 95-113. https://doi.org/10.1016/j. chemgeo.2003.07.002

KULONGOSKI, J.T.; HILTON, D.R.; SELAOLO, E.T. 2004. Climate variability in the Botswana Kalahari from the late Pleistocene to the present day. Geophysical Research Letters, 31(10): L10204. https://doi. org/10.1029/2003GL019238

LEHMANN, B.; PURTSCHERT, R., 1997. Radioisotope dynamics - the origin and fate of nuclides in groundwater. Applied Geochemistry, 12(6): 727-738. https://doi. org/10.1016/S0883-2927(97)00039-5

LEHMANN, B.E.; LOOSLI, H.H.; RAUBER, D.; THONNARD, N.; WILLIS, R.D. 1991. ${ }^{81} \mathrm{Kr}$ and ${ }^{85} \mathrm{Kr}$ in ground water, Milk River aquifer, Alberta, Canada. Applied Geochemistry, 6(4): 419-423. https://doi.org/10.1016/08832927(91)90041-M

LEHMANN, B.E.; DAVIS, S.N.; FABRYKAMARTIN, J.T. 1993. Atmospheric and subsurface sources of stable and radioactive nuclides used for ground-water dating. Water Resources Research, 29(7): 2027-2040. https://doi.org/10.1029/93WR00543

LEHMANN, B.E.; LOVE, A.; PURTSCHERT, R.; COLLON, P.; LOOSLI, H.H.; KUTSCHERA, W.; BEYERLE, U.; AESCHBACHHERTIG, W.; KIPFER, R.; FRAPE, S.K.; HERCZEG, A.; MORAN, J.; TOLSTIKHIN, I.; GRÖNING, M. 2003. A comparison of groundwater dating with ${ }^{81} \mathrm{Kr},{ }^{36} \mathrm{Cl}$ and ${ }^{4} \mathrm{He}$ in four wells of the Great Artesian Basin, Australia. Earth and Planetary Science Letters, 211(3-4): 237-250. https://doi. org/10.1016/S0012-821X(03)00206-1

LEHMANN, B.E.; OESCHGER, H.; LOSSLI, H.H.; HURST, G.S.; ALLMAN, S.L.; KRAMER, S.D.; PAYNE, M.G.; PHILLIPS, R.C.; WILLIS, R.D.; THONNARD, N. 1985. Counting $81 \mathrm{Kr}$ atoms for analysis of groundwater. Journal of Geophysics Research, 90(B13): 1985.

LOOSLI, H.H. 1983. A dating method with ${ }^{39} \mathrm{Ar}$. Earth and Planetary Science Letters, 63(1): 51-62. https://doi.org/10.1016/0012$821 \mathrm{X}(83) 90021-3$ 
LOOSLI, H.H.; OESCHGER, H. 1968. Detection of $\mathrm{Ar}$ in atmospheric argon. Earth and Planetary Science Letters, 5: 191-198. https:// doi.org/10.1016/S0012-821X(68)80039-1

LOOSLI, H.H.; OESCHGER, H. 1969. ${ }^{37} \mathrm{Ar}$ and ${ }^{81} \mathrm{Kr}$ in the atmosphere. Earth and Planetary Science Letters, 7(1): 67-71. https://doi. org/10.1016/0012-821X(69)90014-4

LU, T.; SCHLOSSER, P.; SMETRHIE JR., W.M.; STURCHIO, N.C.; FISCHER, T.P.; KENNEDY, B.M.; PURTSCHERT, R.; SEVERINGHAUS, J.P.; SOLOMON, D.K.; TANHUA, T.; YOKOCHI, R. 2014. Tracer applications of noble gas radionuclides in the geosciences. Earth-Science Reviews, 138: 196-214. https://doi.org/10.1016/j. earscirev.2013.09.002

LUCAS, L.L.; UNTERWEGER, M.P. 2000. Comprehensible review and critical half-life of tritium. Journal of Research of the National Institute of Standards and Technology, 105(4): 541-549. https://doi.org/10.6028/jres.105.043

MAMYRIN, B.A.; TOLSTIKHIN, I.N. 1984. Helium isotopes in nature. Vol. 3. Elsevier, Amsterdam, Oxford, New York, Tokyo.

MAMYRIN, B.A.; TOLSTIKHIN, I.N.; ANUFRIEV, G.S.; KAMANSKIY, I.L. 1969. Anomalous Isotopic Composition of Helium in Volcanic Gases. Doklady Akademii Nauk S.S.S.R., 184: 1197-1199.

MARINE, I.W. 1979. The use of naturally occurring helium to estimate ground water velocities for studies of geologic storage of radioactive waste. Water Resources Research, 15(5): 1130-1136. https://doi.org/10.1029/ WR015i005p01130

MATSUMOTO, T. 2018. Training Course on the Use of Noble Gases in Hydrological Studies. International Atomic Energy Agency (IAEA), Vienna.

MATSUMOTO, T.; SOLOMON,D.K.; ARAGUÁS, L.A; AGGARWAL, P. 2017. The IAEA's Coordinated Research Project on "Estimation of Groundwater Recharge and Discharge by Using the Tritium, Helium-3 Dating Technique". Geochemical Journal, 51(5): $385-$ 390. https://doi.org/10.2343/geochemj.2.0500
MATSUMOTO, T.; CHEN, Z.; WEI, W.; YANG, G-M.; HU, S-M.; ZHANG, X. 2018. Application of combined ${ }^{81} \mathrm{Kr}$ and ${ }^{4} \mathrm{He}$ chronometers to the dating of old groundwater in a tectonically active region of the North China Plain. Earth and Planetary Science Letter, 493: 208-217. https://doi.org/10.1016/j. epsl.2018.04.042

MAZOR, E. 1972. Paleotemperatures and other hydrological parameters deduced from gases dissolved in ground waters, Jordan Rift Valley, Israel. Geochimica et Cosmochima Acta, 36(12): 1321-1336. https://doi. org/10.1016/0016-7037(72)90065-8

MEI, D.-M.; YIN, Z.-B.; SPAANS， J.; KOPPANG,M.; HIME, A.; KELLER, C. ; GEHMAN.V.M. 2010. Prediction of underground argon content for dark matter experiments. Physical Review C, 81: 055802. https://doi.org/10.1103/physrevc.81.055802

MERCURY, L.; PINTI, D.L.; ZEYEN, H. 2004. The effect of the negative pressure of capillary water on atmospheric noble gas solubility in ground water and palaeotemperature reconstruction. Earth and Planetary Science Letters, 223(1-2): 147-161. https://doi. org/10.1016/j.epsl.2004.04.019

MOMOSHIMA, N.; INOUE, F.; OHTA, T.; MAHARA, Y.; SHIMADA, J.; IKAWA, R.; KAGABU, M.; ONO, M.; YAMAGUCHI, K.; SUGIHARA, S.; TANIGUCHI, M. 2011. Applications of ${ }^{85} \mathrm{Kr}$ dating to groundwater in volcanic aquifer of Kumamoto Area, Japan. Journal of Radioanalytical and Nuclear Chemistry, 287: 761-767. https://doi. org/10.1007/s10967-010-0821-0

NEWMAN, B.C.; OSENBRÜCK, K.; AESCHBACH-HERTIG, W.; D. KIP SOLOMON, D.K.; COOK, P.; RÓŻAŃSKI, K.; KIPFER, R. 2010. Dating of 'young' groundwaters using environmental tracers: advantages, applications, and research needs. Isotopes in Environmental and Health Studies, 46(3): 259-278. https://doi.org/10.108 $0 / 10256016.2010 .514339$

OHTA, T.; MAHARA, Y.; MOMOSHIMA, N.; INOUE, F.; SHIMADA, J.; IKAWA, R.; TANIGUCHI, M. 2009. Separation of dissolved $\mathrm{Kr}$ from a water sample by means 
of a hollow fiber membrane. Journal of Hydrology, 376(1-2): 152-158. https:/doi. org/10.1016/j.jhydrol.2009.07.022

O’NIONS, R.K.; OXBURGH, E.R. 1988. Helium, volatile fluxes and the development of continental crust. Earth and Planetary Science Letters, 90(3): 331-347. https://doi. org/10.1016/0012-821X(88)90134-3

OZIMA, M.; PODOSEK, F.A. 2002. Noble gas geochemistry. Cambridge University Press, Cambridge, London, New York, $2^{\text {nd }}$ Edition, $302 \mathrm{p}$.

PATTERSON, L.J.; STURCHIO, N.C.; MACK KENNEDY, B.; VAN SOEST, M.C.; SULTAN, M.; LU, Z-T; LEHMANN, B.; PURTSCHERT, R.; EL ALFY, Z.; EL KALIOUBY, B.; DAWOOD, Y.; ABDALLAH, A. 2005. Cosmogenic, radiogenic, and stable isotopic constraints on groundwater residence time in the Nubian Aquifer, Western Desert of Egypt. Geochemistry, Geophysics, Geosystems, 6(1): 1-19. https://doi.org/10.1029/2004GC000779

PEETERS, F.; BEYERLE, U.; AESCHBACHHERTIG, W.; HOLOCHER, J.; BRENNWALD, M.S.; KIPFER, R. 2002. Improving noble gas based paleoclimate reconstruction and ground water dating using ${ }^{20} \mathrm{Ne} /{ }^{22} \mathrm{Ne}$ ratios. Geochimica et Cosmochimica Acta, 67(4): 587-600. https:// doi.org/10.1016/S0016-7037(02)00969-9

PHILLIPS, F.M.; CASTRO, M.C. 2003. Groundwater dating and residence time measurements. In: K. Turekian \& H. Holland (ed) Treatise on Geochemistry, Elsevier Science, p. 451-497. https://doi.org/10.1016/ B0-08-043751-6/05136-7

PHILLIPS, F.M.; TANSEY, M.K.; PEETERS, L.A.; CHENG, S.; LONG, A. 1989. An isotopic investigation of groundwater in the central San Juan Basin, New Mexico: Carbon-14 dating as a basis for numerical flow modeling. Water Resources Research, 25(1): 2259-2273. https://doi.org/10.1029/WR025i010p02259

PINTI, D.L.; MARTY, B. 1998. The origin of helium in deep sedimentar aquifers and the dating very old groundwaters. In: J. Parnell (ed.) Dating and Duration of Fluid Flow and
Fluid-Rock Interaction. Geological Society, London, Special Publications, 144, 53-68.

PLUMMER, L.N.; EGGLESTON, J.R.; ANDREASEN, D.C.; RAFFENSPERGER, J.P.; HUNT, A.G.; CASILE, G.C. 2012. Old groundwater in parts of the upper Patapsco aquifer, Atlantic Coastal Plain Maryland, USA: evidence from radiocarbon, chlorine-36 and helium-4. Hydrogeology Journal, 20(7): 1269-1294. https://doi.org/10.1007/s10040012-0871-1

PORCELLI, D.; BALLENTINE, C.J. (ed) 2002. Models for Distribution of Terrestrial Noble Gases and Evolution of the Atmosphere. Reviews in Mineralogy and Geochemistry, 47(1): 411-480. https://doi.org/10.2138/ rmg.2002.47.11

PORCELLI, D.; BALLENTINE, C.J.; WIELER, R. 2002. An Overview of Noble Gas Geochemistry and Cosmochemistry. Reviews in Mineralogy and Geochemistry, 47(1): 1-19. https://doi.org/10.2138/rmg.2002.47.1

PROBST, P.; YOKOCHI, R.; STURCHIO, N.C. 2006. Method for extraction of dissolved gases from groundwater for radiokrypton analysis. Eos Trans. AGU 87 (52) [Fall Meet. Suppl., Abstract H41B-0414].

PROBST, P.C.; YOKOCHI, R.; STURCHIO, N.C. 2007. Method for Extraction of Dissolved Gases from Groundwater for Radiokrypton Analysis. In: Mini Conference on Noble Gases in the Hydrosphere and in Natural Gas Reservoirs, 4, Potsdam, Germany. Disponível em: http:// bib.gfz-potsdam.de/pub/minoga/minoga conference_proceedings_070215-c.pdf

PROFILL ENGENHARIA E AMBIENTE S.A. 2019. Plano de monitoramento qualiquantitativo das águas subterrâneas da Bacias PCJ. Produto 2-V03 - Diagnóstico Hidrogeológico das Bacias PCJ. Agência das Bacias PCJ, Piracicaba, 199 p.

PURTSCHERT, R.; YOKOCHI, R.; STURCHIO, N.C. 2013. Kripton-81 dating of old groundwater. In: A. Suckow, P.K. Aggarwal, L.J. Araguas-Araguas (eds) Isotope Methods for Dating Old Groundwater. Vienna, IAEA, cap. 5, p. 91-124. 
RUDOLPH, J.; RATH, H.K.; SONNTAG, C. 1984. Noble gases and stable isotopes in 14C-dated palaeowaters from central Europa and the Sahara In: IAEA, ISOTOPE HYDROLOGY-1983

(IAEA-SM-270),

Vienna, p. 467-477.

SCHLOSSER, P.; STUTE, M.; DÖRR, H.; SONNTAG, C.; MÜNNICH, K.O. 1988. Tritium $/{ }^{\beta} \mathrm{He}$ dating of shallow groundwater. Earth and Planetary Science Letters, 89(34): 353-362. https://doi.org/10.1016/0012$821 X(88) 90122-7$

SCHLOSSER, P.; STUTE, M.; SONNTAG, C.; MÜNNICH, K.O. 1989. Tritiogenic ${ }^{3} \mathrm{He}$ in shallow ground water. Earth and Planetary Science Letters, 94(3-4): 245-256. https://doi. org/10.1016/0012-821X(89)90144-1

SELTZER, A.M; STUTE, M.; MORGENSTERN, U.; STEWART, M.K; SCHAEFER, J.M. 2015. Mean annual temperature in New Zealand during the last glacial maximum derived from dissolved noble gases in groundwater. Earth and Planetary Science Letters, 431: 206-216. https://doi.org/10.1016/j.epsl.2015.09.032

SILVA Jr, G.C.; PITA, R.C.S.; CUNHA, F.C.M.B.; SILVA, T.A. 2021. Aplicação do Isótopo Radioativo de Carbono $\left({ }^{14} \mathrm{C}\right)$ na Determinação de Tempos de Residência em Aquíferos. Derbyana, 42: e740.

SMETHIE JR, W.M.; SOLOMON, D.K.; SCHIFF, S.L.; MATHIEU; G.G. 1992. Tracing groundwater flow in the Borden aquifer using krypton-85. Journal of Hydrology, 130(14): 279-297. https://doi.org/10.1016/00221694(92)90114-B

SMITH, S.P.; KENNEDY, B.M. 1983. The solubility of noble gases in water and in $\mathrm{NaCl}$ brine. Geochimica et Cosmochima Acta, 47(3): 503-515. https://doi.org/10.1016/00167037(83)90273-9

SOLOMON, D.K; HUNT, A.; POREDA, R.J. 1996. Source of radiogenic helium 4 in shallow aquifers: Impications for dating young groundwater. Water Resources Research, 32(6): 1805-1813. https://doi. org/10.1029/96WR00600
STURCHIO, N.; DU, X.; PURTSCHERT, R.; LEHMANN, B.E.; SULTAN, M.; PATTERSON, L.J.; LU, Z.; MÜLLER, P.; BIGLER, T.; BAILEY, K.; O'CONNOR, T.P.; YOUNG, L.; LORENZO, R.; BECKER, R.; ELALFY,Z.; EL KALIOUBY,B.; DAWOOD, Y.; ABDALLAH, A.M.A. 2004. One million year old groundwater in the Sahara revealed by krypton- 81 and chlorine-36. Geophysical Research Letters, 31(5): L05503. https:/doi. org/10.1029/2003GL019234

STUTE, M. 1989. Edelgase im GrundwasserBestimmung von Paläotemperaturen und Untersuchung der Dynamik von Grundwasserfliesssystemen. Universität Heidelberg, Heidelberg, PhD dissertation.

STUTE, M; SCHLOSSER, P. 2000. Atmospheric noble gases. In: P. Cook \& A.L. Herczeg (eds) Environmental tracers in subsurface hydrology. Kluwer Academic Publishers, Boston, p. 349-377.

STUTE, M.; SCHLOSSER, P. 1993. Principles and Applications of the Noble Gas Paleothermometer. In: P.K. Swart; K.C. Lohmann; J. Mckenzie; S. Savin (ed) Climate Change in Continental Isotopic Records (Geophysical Monograph 78). American Geophysical Union, Washington, DC, p. 89100. https://doi.org/10.1029/GM078p0089

STUTE, M.; TALMA, A.S. 1998. Glacial temperatures and moisture transport regimes reconstructed from noble gases and delta ${ }^{18} \mathrm{O}$, Stampriet aquifer, Namibia. In: Isotope techniques in the study of environmental change (IAEA-SM-349), IAEA, Vienna, p. 307-318

STUTE, M.; SONNTAG, C.; DÉAK, J.; SCHLOSSER, P. 1992. Helium in deep circulating groundwater in the Great Hungarian Plain - Flow dynamics and crustal and mantle helium fluxes. Geochimica et Cosmochimica Acta, 56(5): 2051-2067. https:// doi.org/10.1016/0016-7037(92)90329-H

STUTE, M.; FORSTER, M.; FRISCHKORN, H.; SEREJO, A.; CLARK, J.F.; SCHLOSSER, P.; BROECKER, W.S.; BONANI, G. 1995. Cooling of tropical Brazil $\left(5{ }^{\circ} \mathrm{C}\right)$ during the Last Glacial Maximum. Science, 
269(5222): 379-383. https://doi.org/10.1126/ science.269.5222.379

SUN, T.; HALL, C.M.; CASTRO, M.C.; LOHMANN, K.C.; GOBLET, P. 2008. Excess air in the noble gas groundwater paleothermometer: A new model based on diffusion in the gas phase. Geophysical Research Letters, 35: L19401. https://doi. org/10.1029/2008GL035018

THONNARD, N.; WILLIS, R.D.; WRIGHT, M.C.; DAVIS, W.A.; LEHMANN, B.E. 1987. Resonance ionization spectroscopy and the detection of ${ }^{81} \mathrm{Kr}$. Nuclear Instrument Methods, B29: 398-406. https://doi. org/10.1016/0168-583X(87)90273-4

THONNARD, N.; MCKAY, L.D.; CUMBIE, D.H.; JOYNER, C.F. 1997. Status of laser-based krypton-85 analysis development for dating of young ground water. The Geological Society of America, Abstracts, 29(6): A-78.

TOLSTIKHIN, I.N.; KAMENSKY, I.K. 1969. Determination of groundwater ages by the $\mathrm{T}-{ }^{3} \mathrm{He}$ method. Geochemistry International, 6: 810-811.

TOLSTIKHIN, I.; LEHMANN, B.E.; LOOSLI, H.H.; GAUTSCHI, A. 1996. Helium and argon isotopes in rocks, minerals, and related ground waters: A case study in northern Switzerland. Geochimica et Cosmochimica Acta, 60(9): 1497-1514. https://doi.org/10.1016/00167037(96)00036-1

TORGERSEN, T. 1980. Controls on pore-fluid concentration of ${ }^{4} \mathrm{He}$ and ${ }^{222} \mathrm{Rn}$ and the calculation of ${ }^{4} \mathrm{He}{ }^{222} \mathrm{Rn}$ ages. Journal of Geochemical Exploration, 13(1): 57-75. https://doi.org/10.1016/0375-6742(80)90021-7

TORGERSEN, T. 1989. Terrestrial degassing fluxes and the atmospheric helium budget: Implications with respect to the degassing processes of continental crust. Chemical Geology: Isotope Geoscience Section, 79(1): 1-14. https://doi.org/10.1016/01689622(89)90002-X

TORGERSEN, T.; CLARKE, W.B. 1985. Helium accumulation in ground water, I: An evaluation of sources and the continental flux of crustal ${ }^{4} \mathrm{He}$ in the Great Artesian Basin,
Australia. Geochimica et Cosmochimica Acta, 49(5): 1211-1218. https://doi.org/10.1016/00167037(85)90011-0

TORGERSEN, T.; IVEY, G.N. 1985. Helium accumulation in ground water, II: A model for the accumulation of the crustal ${ }^{4} \mathrm{He}$ degassing flux. Geochimica et Cosmochimica Acta, 49(11): 2445-2452. https://doi. org/10.1016/0016-7037(85)90244-3

TORGERSEN, T.; STUTE, M. 2013. Helium (and other noble gases) as a tool for understanding long time groundwater transport. In: A. Suckow, P.K. Aggarwal, L.J. AraguasAraguas (eds.) Isotope Methods for Dating Old Groundwater. Vienna, IAEA, cap. 8, p. 179-216.

TORGERSEN, T.; PURTSCHERT, R.; PHILLIPS, F.M.; PLUMMER, L.N.; SANFORD, W.E.; SUCKOW, A. 2013. Defining Groundwater Age. In: A. Suckow, P. K. Aggarwal, L.J. Araguas-Araguas (eds.) Isotope Methods for Dating Old Groundwater. Vienna, IAEA, cap. 3, p. 21-32.

\section{USGS - UNITED STATES GEOLOGICAL} SURVEY. 2019. The Reston Groundwater Dating Laboratory. ${ }^{3} \mathrm{H} /{ }^{3} \mathrm{He}$ Noble Gas Sampling. Disponível em: https://water.usgs. gov/lab/3h3he/sampling/

WEI, W.; AESCHBACH-HERTIG, W.; CHEN, Z. 2015. Identification of $\mathrm{He}$ sources and estimation of He ages in groundwater of the North China Plain. Applied Geochemistry, 63: $182-189$. https://doi.org/10.1016/j. apgeochem.2015.08.010

WEISE, S.; MOSER, H. 1987.Ground water dating with helium isotopes. In: Isotope techniques in water resources development. IAEA, Vienna, p. 105-126.

WEISS, R.F. 1970. The solubility of nitrogen, oxygen and argon in water and seawater. Deep Sea Research and Oceanographic Abstracts, 17(4): 721-735. https://doi.org/10.1016/00117471(70)90037-9

WEISS, R.F. 1971. Solubility of helium and neon in water and seawater. Journal of Chemical and Engineering Data, 16(2): 235-241. https://doi. org/10.1021/je60049a019 
WEISS, R.F.; KYSER, T.K. 1978. Solubility of krypton in water and seawater. Journal of Chemical and Engineering Data, 23(1): 6972. https://doi.org/10.1021/je60076a014

WELTE, J.; RITTERBUSCH, F.; STEINKE, I.; HENRICH, M.; AESCHBACH-HERTIG, W; OBERTHALER, M.K. 2010. Toward the realization of atom trap trace analysis for ${ }^{39} \mathrm{Ar}$. New Journal of Physics, 12: 065031. https:// doi.org/10.1088/1367-2630/12/6/065031

WEYHENMEYER, C.E.; BURNS, S.J.; WABER, H.N.; AESCHBACH-HERTIG, W.; KIPFER, R.; LOOSLI, H.H.; MATTER, A. 2000. Cool glacial temperatures and changes in moisture source recorded in Oman ground waters. Science, 287(5454): 842-845. https://doi. org/10.1126/science.287.5454.842

WINGER, K.; FEICHTER, J.; KALINOWSKI, M.B.; SARTORIUS, H.; SCHLOSSER, C. 2005. A new compilation of the atmospheric ${ }^{85}$ krypton inventories from 1945 to 2000 and its evaluation in a global transport model. Journal of Environmental Radioactivity, 80(2): 183-215. https://doi.org/10.1016/j. jenvrad.2004.09.005

YANG, G.-M.; CHENG, C.-F.; JIANG, W.; LU, Z.-T.; PURTSCHERT, R.; SUN, Y.-R.; TU, L.-Y.; HU, S.-M. 2013. Analysis of ${ }^{85} \mathrm{Kr}$ : a comparison at the $10^{-14}$ level using micro-liter samples. Scientific Reports, 3: 1596. https:// doi.org/10.1038/srep01596.

YOKOCHI, R. 2016. Recent developments on field gas extraction and sample preparation methods for radiokrypton dating of groundwater. Journal of Hydrology, 540: 368-378. http:// dx.doi.org/10.1016/j.jhydrol.2016.06.020

YOKOCHI, R.; HERATY, L.J.; STURCHIO, N.C. 2008. Method for purification of krypton from environmental samples for analysis of radiokrypton isotopes. Analytical Chemistry, 80(22): 8688. https://doi.org/10.1021/ ac $801804 x$

\section{Endereço dos autores:}

Roberto Eduardo Kirchheim - CPRM/Serviço Geológico do Brasil, Rua Costa, 55, Cerqueira César, CEP: 01304-010, São Paulo, SP, Brasil.E-mail: roberto.kirchheim@cprm.gov.br

Chang Huang Kiang - Laboratório de Estudos de Bacias/Centro de Estudos Ambientais, Universidade Estadual Paulista "Júlio de Mesquita Filho" (UNESP) e Departamento de Geologia Aplicada, Instituto de Geociências e Ciências Exatas/UNESP, Campus de Rio Claro, Av. 24A, 1515, Bairro Bela Vista, CEP: 13506-900, Rio Claro, SP, Brasil. E-mail: chang.hung-kiang@unesp.br

Didier Gastmans - Centro de Estudos Ambientais (CEA), Universidade Estadual Paulista "Júlio de Mesquita Filho" (UNESP), Av. 24A, 1515, Bela Vista, CEP: 13.506-900, Rio Claro, SP, Brasil. E-mail: didier.gastmans@unesp.br

Sibele Ezaki - Instituto Geológico, Secretaria de Infraestrutura e Meio Ambiente, Rua Joaquim Távora, 822, Vila Mariana, CEP: 04015-011, São Paulo, SP, Brasil.E-mail: sibezaki@sp.gov.br

Márcia Regina Stradioto - Laboratório de Estudos de Bacias, Universidade Estadual Paulista "Júlio de Mesquita Filho" (UNESP), Campus de Rio Claro, Av. 24-A, 1515, Bairro Bela Vista, CEP 13506-900, Rio Claro, SP, Brasil.E-mail: marcia.stradioto@unesp.br

Artigo submetido em 14 de abril de 2021, aceito em 19 de junho de 2021. 